\title{
Disrupting Gendered Epistemic Injustice in K-12 mathematics - A Research Synthesis
}

\author{
Priyanka Agarwal
}

The University of California, Los Angeles

\begin{abstract}
Author Note
This manuscript is based upon the work supported by the Mindset Scholars Network's Inclusive Mathematics Environments Early Career Fellowship, with funding provided by a grant from the Bill \& Melinda Gates Foundation. The content is solely the responsibility of the authors and does not necessarily represent the views of the Mindset Scholars Network or the Bill \& Melinda Gates Foundation.
\end{abstract}




\begin{abstract}
Over the last half century, research on gender has consistently debunked male superiority in mathematics. Yet, negation of children and youth on the basis of gender (and race) continue to occur in mathematics education. Scholars have increasingly focused on theorizing and examining ways to make mathematics classrooms more gender-inclusive. In this paper we synthesize prior studies from the lens of gender equity as a form of epistemic justice (Fricker, 2007). We argue that achieving epistemic justice requires an ecological research that seeks the interrelations of micro, meso, and macro levels of inequality and privilege (Weis \& Fine, 2012). Together, these constructs lay the groundwork for mathematics education research to understand how do individuals and institutions negotiate, resist, or disrupt epistemic injustice in mathematics education, as established by heteropatriarchy and Whiteness? We identify six emergent themes that speak to the guiding question while highlighting nuances and complexities of studying gender equity in mathematics education. We conclude with a discussion of implications and future directions for research.
\end{abstract}

Keywords: mathematics, gender, race, heteropatriarchy, epistemic injustice, ecology 


\section{Disrupting Gendered Epistemic Injustice in K-12 mathematics - A Research Synthesis}

The notion of gender equity and mathematics education has shifted over time. Early approaches can be described as focused on achievement gaps (i.e., differential outcomes) or other indications of inherent biological differences between male and female children (e.g., in spatial reasoning). Over the past fifty years or more, research on gender has largely debunked male superiority in mathematics amidst a large body of evidence demonstrating male and female children do not differ in their early quantitative and mathematical abilities (e.g., Else-Quest, Hyde, \& Linn, 2010; Fennema \& Sherman, 1977, 1978; Hanna, 2003; Hutchison, Lyons, \& Ansari, 2018; Kersey, Braham, Csumitta, Libertus, \& Cantlon, 2018; Kersey, Csumitta, \& Cantlon, 2019; Lindberg, Hyde, Petersen, \& Linn; 2010; Vale \& Bartholomew, 2008).

The second approach to gender equity in mathematics education research has focused on opportunity gaps (i.e., differential access - e.g., Ansell and Doerr, 2000). This conception of equity largely looked to the way contextual and cultural factors might account for differences in students' mathematical engagement, learning outcomes, and course-taking choices by gender (e.g., Else-Quest, Hyde, \& Linn, 2010). Among the contextual and cultural factors that have been described are, for example, gendered expectations of parents and teachers (e.g., Birenbaum \& Nasser, 2006; Hyde and Jaffee, 1998); gender socialization beginning in early-childhood in families and schools (e.g., Blaise, 2005, 2012; Blaise \& Taylor, 2012; Brandon, Newton, \& Hammond, 1987; Dossi, Figlio, Giuliano, \& Sapienza, 2019); and implicit biases that result in differential treatment (discursively and through curricula) and thus a differential in how the learning environment is experienced (e.g., Lester, Yamanaka, \& Struthers, 2016; Leyva, 2016; Riegle-Crumb \& Humphries, 2012). This body of research has, at times, looked at the ways patriarchy undervalues girls' excellence in mathematics, and when combined with White supremacy, the undervaluation of racially minoritized girls in particular (Code, 1991; Harding, 1991/2016; Hottinger, 2016; Nelson, 1990/2010). 
The third and final approach to gender equity builds on the opportunity gap literature but thinks more consistently about the role of ideology (gender, race, class) and its interrelations with how school children experience mathematics moment-to-moment and over time in schools (e.g., Esmonde, 2011; Gholson, 2016; Gholson \& Martin, 2019; Leyva, 2016; Mendick, 2006; Rands, 2009; Sengupta-Irving \& Vossoughi, 2019). Among the many contributions of this latter work, is its close attention to the diversity of discursive and embodied ways children know and do mathematics, and how they experience erasure or harm when their ways differ from the normative expectations of dominant masculinity and Whiteness. This approach thus allows for an examination of the deep harms to people's identity, agency, and dignity in mathematics learning, which in turn negatively impact their access, performance, and persistence within the domain.

Given the long arc of prior mathematics education research on gender equity, harm and negation of youth on the basis of gender-though seldom gender alone-remain. Thus it is timely, if not urgent, that we seek more robust directions for research and practice. In this paper we look for way ahead based on a synthesis of prior studies and advance a view of gender equity as a form of epistemic justice (Fricker, 2007). Further, we argue that achieving such epistemic justice requires an ecological research that seeks the interrelations of micro, meso, and macro levels of inequality and privilege (Weis \& Fine, 2012. Together, these constructs lay the groundwork for mathematics education research to understand how individuals and institutions reproduce, disrupt or resist pernicious ideologies that perpetuate harm and preclude the establishment of gender-inclusive mathematics learning experiences. In the next section, we provide an overview of epistemic justice before presenting the conceptual framework and definition of terms that guide this review.

\section{Epistemic (In)Justice}

Drawing on Fricker (2007), we conceptualize gender equity in mathematics as an issue of epistemic justice, rights, and desire: the right and desire to knowledge, to knowing, to learning, and to 
being in ways uncompromised by larger sociopolitical formations of gender, race, and class. As Fricker describes, the denial of such rights is, epistemic injustice-a harm done to people's very capacity as knowers. Fricker's emphasis on epistemic injustice as a harm makes clear the virulent and pernicious nature of what can be obscured in the more benign language of "gender socialization" or "gender bias" in mathematics education research. Experiencing a denial or erasure of one's self is a moral and political harm that carries the weight of centuries of symbolic, visceral, and epistemic violence perpetrated on gender(race) minoritized $^{1}$ communities (Clisby \& Holdsworth, 2014; de Leeuw, 2016; de Medicci, 2006; Fluri, J. L., \& Piedalue, 2017; Giuliano, 2017; Marcus, 1988; Tyack, 1993; Whitfield, 1995). Epistemic violence is a discursive practice of silencing and othering through which minoritized persons are first constructed and then excluded from the processes of knowledge formation (Bunch, 2015; Dotson, 2011; Rawls \& David, 2003). Over time, the practice of epistemic violence shapes rigid cultural narratives about the nature of knowledge, what forms of knowledge to value, who participates in shaping and benefiting from the knowledge produced, and who is harmed by their exclusion or erasure.

Advancing gender equity as a form of epistemic justice invites a closer examination of the ideologies and processes that establish harm or erasure for gender(race) minoritized students in mathematics, as well as opportunities for disruption, resistance, and transformation. This standpoint raises important questions that are only just beginning to emerge in the field: How do gender(race) minoritized students negotiate and resist epistemic harm in the moment-to-moment and everyday of mathematics learning? How might institutions and institutional agents disrupt epistemic harm as messaged through norms, curricula and pedagogy? What might the absence of epistemic injustice look,

\footnotetext{
${ }^{1}$ Knowing that language matters, and that it is both freeing and limiting, we will most often use the phrase 'gender(race) minoritized' even as it masks the heterogeneity of gender, race and sexuality it is being used to capture. We use the term gender(race) minoritized in reference to cisgender girls/women, LGBTIQA, gender fluid or gender non-conforming persons, and as consequentially overlapping with racial minoritization. In using this term we wish to foreground issues of heteropatriarchy while recognizing its complex relation with white supremacy, colonialism, settler colonialism and capitalism.
} 
sound and feel like? By amplifying epistemic justice as a basis for gender equity research in mathematics education, this review of research asks: How do individuals and institutions negotiate, resist, or disrupt epistemic injustice in mathematics education, as established by heteropatriarchy ${ }^{2}$ and Whiteness? In asking this question, we are also following Eve Tuck (2009)'s call to suspend damage-centered research and instead review the past research to construct desire-based theories of transformation that seeks wisdom, complexities, intersectionality, and multiplicity of gender in mathematics.

Based on a synthesis of thirty years of research, this review provides insights on the nuances and complexities of studying gender equity in mathematics education. We will discuss how different theoretical perspectives advance efforts at creating inclusive learning environments (in and beyond schools). In what follows, I define gender for the purposes of this review by drawing on feminist, queer, and critical race theories. I then situate the relation between the common constructs of gender bias and stereotype threat in mathematics education with the notion of epistemic injustice. After explaining the methodology of review, I identify six emergent themes that speak to the question: How do individuals and institutions negotiate, resist, or disrupt epistemic injustice in mathematics education, as established by heteropatriarchy and Whiteness? Finally, I discuss implications and future directions for research in gender equity in mathematics education.

\section{Conceptual Framework}

\section{Gender as Dynamic, Fluid, and Socially-Constructed}

Gender has long been considered a uniform genetically-determined binary construct to describe people as males or females (i.e., sex category). This has been contested by instead drawing distinctions between sex (chromosomes, genital anatomy, and other biologically or genetically determined features)

\footnotetext{
${ }^{2}$ In feminist theory, heteropatriarchy (etymologically from heterosexual and patriarchy) is a socio-political system where (primarily) cisgender males and heterosexuals have authority over cisgender females and over other sexual orientations and gender identities.
} 
and gender (psychological, behavioral, and cultural ways of being associated with a sex category). Still, the belief that men and women are biologically different in their behaviors, psychology, and practices exists. For example, one perspective in feminism posits that men and women have different ways of knowing (Belenky et al., 1986/1997; Becker, 1995; Boaler, 1997b; Becker \& Jacobs, 2001; Burton, 1995; Jacobs \& Becker, 1997). This suggests that girls and women as a group share uniform characteristics and ways in which they act, think, and learn; and that these practices are characteristically different from those of men's. Historically originating as White middle-class Western feminism, the construction of women as a uniform collective group aimed to confront patriarchy or sexism, i.e., systematic discrimination against females or disparaging view of femaleness and femininity. It values men, maleness or masculinity over women, femaleness or femininity (Airton, 2009).

The account of gender as a uniform biologically-determined construct has been argued to be too narrow to fully capture issues of heteropatriarchy (the dominance of cisgender heterosexual men in society). It has been challenged on two accounts: first, it fails to consider place, culture, class, and racebased particularities in people's ways of knowing and doing - that women (and men) across cultures may differ in their practices; second, it does not take into consideration non-binary, mutable, and fluid nature of gender (Stanford Encyclopedia of Philosophy). As such, White western feminism does not directly confront gendered racism and genderism. Drawing on Airton (2009), Esmonde (2011) defines genderism as "the valuing of people who are seen as locally gender normative (e.g., people who look, act and speak like women are expected to in a given cultural context) over people who are seen as nonnormative" (p. 29). Gender non-normativity is linked to gender identity and gender expression. The Human Rights Campaign, an LGBTQ civil rights organization, defines gender identity as "one's innermost concept of self as male, female, a blend of both or neither - how individuals perceive themselves and what they call themselves. One's gender identity can be the same or different from their sex assigned at birth" and gender expression as "external appearance of one's gender identity, usually expressed 
through behavior, clothing, haircut or voice, and which may or may not conform to socially defined behaviors and characteristics typically associated with being either masculine or feminine."

Esmonde further explains that everyone is affected by genderism:

Genderism can be considered in relation to other forms of oppression, including sexism, homophobia, and transphobia. A focus on genderism does not negate a concern for sexism or misogyny (the valuing of men/maleness/masculinity over women/femaleness/femininity). Rather, genderism highlights the ways in which those who are oppressed by sexism may still be privileged by genderism. For example, gender normative women may obtain privilege "as a consequence of correctly and seamlessly approximating what it means to be that gender in that place and time" (Airton, 2009, p. 240). Genderism is related to homophobia (fear or hatred of queer people) and transphobia (fear or hatred of gender non-conforming people) because these forms of oppression are often reactions against gender non-normativity. For example, calling a boy a sissy is a way to point out that the boy is not living up to gender norms. (p. 29) In the above example, calling a boy sissy is also a reminder that boys must not act in stereotypical feminine ways and instead must affirm to their more privileged and valued masculine ways, thus reaffirming sexist views. Esmonde thus illustrates how sexism and genderism together uphold heteropatriarchy.

Similar to the way Esmonde (2011) writes of the interlocking nature of subjugation and privilege, an interdisciplinary body of literature has grown to document ways in which people facing sexism and genderism in mathematics education experience subjugation/privilege as associated with, for example, race, ethnicity, class, language, dis/ability and global location (Barnes, 2000; Cho, Crenshaw, \& McCall, 2013; Crenshaw, 1989, 1991; Esmonde, Brodie, Dookie, \& Takeuchi, 2009; Leyva, 2016; Riegle-Crumb,2006; Riegle-Crumb \& Humphries, 2012; Wolfe, 2019). It is argued that gender dynamics do not play out in isolation of other socially constructed identities. For example, positioning a 
Black girl as 'loud' or a Black boy as 'deviant' serves as a reminder that they are not meeting the standards of being girls and boys considered more appropriate from the dominant White perspective. Consider Gholson and Martin's (2014) use of Intersectionality (Crenshaw, 1989, 1991) to study a group of third grade girls in an all Black school. Through social network analysis, the authors highlight how the construction of girls as smart/Black/mean/bully intersects with their changing mathematical identities. The authors illustrate how Shawna's more prominent bully behavior (as against Mia's subtly mean behavior including gossiping, exclusion, or verbal insults) and Shawna's darker skin, shorter hair, and heavier stature (as against Mia's lighter skin, long hair, and thinness) positioned her unfavorably within the social network and left her "academically invisible" to her peers (p. 30). Shawn's academic invisibility belied how she almost always scored higher than others in her mathematics class, just like Mia. So, Mia's talk and physical characteristics that implicitly positioned her in closer relation to Whiteness and in turn, as mathematically competent. The authors argue that Blackhood or girlhood are more than simple identity markers. Implicit within these identities is a construction of Blackness in relation to mathematics that is dominantly recognized as aligned with Whiteness. As described, the interlocking nature of race/racism and sex/sexism that Intersectionality theory affords made visible the complex and nuanced dimensions of girlhood and Blackness as against Whiteness and Whiteness in mathematics.

Scholars from philosophical and sociological traditions have delineated the idea of gender as a performance and differentiating it from the uniform essentialist (genetically-determined) view of gender (Fenstermaker, \& West, 2013; West \& Zimmerman, 2009). The notion of gender as performance or gendered subjectivity was forwarded as a way to differentiate it from the traditional binary and uniform essentialist views of gender. Gendered subjectivity points out that irrespective of sex or gender identity, we are also always performing gender to fit into the socially constructed and ascribed roles, division of labor, and ethical values that are deemed appropriate or expected within any locally defined cultural context or activity. Here, gender is seen as something that is discursively constructed in social 
interactions, activities, and histories of people, culture, and society that are slow and hard to change (Butler, 1988/2006). Gender is also posited as fluid and dynamic across contexts and over the course of a lifetime. From this perspective, masculinity and femininity are viewed as mutable properties of practices, not a function of sex identity. Studies in this realm have increasingly highlighted the processes of gendered construction of children and youth in mathematics as a reflection of their environment and the implications that such social constructions have for their learning and choice-making (e.g., Bartholomew, 2005; Boaler, 2002; Esmonde, 2011; Kaplan, 2013; Mendick, 2006; Walls, 2010). For example, Kaplan's (2013) dissertation study presents rich stories of how three middle-school females use an amalgam of course grades, participation in class discussion and small-group work, relationships with the teacher, parents' narratives of their math skills, and the importance of mathematics for college and career, to construct their actual and future mathematics identities in relation to their gender and race.

Furthermore, queer theories argue for a non-binary notion of sex itself (Butler, 1990, 1993). That, within the biological sex of female and male itself there is considerable variability in the identities individuals of any sex may hold. In fact, even within the biologically-defined sex characteristics, individuals may be born with variations in chromosomes, gonads, sex hormones, or genitals that, according to the UN Office of the High Commissioner for Human Rights, "do not fit the typical definitions for male or female bodies". This itself makes sex classification as something that occurs on a spectrum of varying degrees of maleness and femaleness (Stone, 2007). It is often not just the chromosomal or genital anatomy, but the whole genetic makeup, functions of these genes during development, and most importantly, life experiences that make people who they are and how they recognize being a man, woman, trans, intersex, or gender-queer (Intersex Society of North America). As noted above, life experience themselves vary by individual's cultural identity, community relations, race, ethnicity, class, 
place, religion, and so much more; it all informs an individual's ways of knowing and being (Coffey \& James, 2016; Esmonde, 2011; Mendick, 2006; Francis, 2010).

In this review, gender is dynamic, fluid, and socially constructed; gender is performed differently across locally situated cultural contexts and along spectrum of more or less feminine/masculine. The dearth of research on sexuality means the review offers little insight specific to inclusive mathematics learning environments for lesbian, gay and bisexual students, an issue of importance to which we return in the discussion.

\section{Relation between Gender Bias and Epistemic Injustice}

To understand the relation between gender-related prejudices and epistemic injustice, feminist social epistemologists have leveraged the notion of epistemic agency (Code 1991; Fricker, 2007; also Lave, 1988). Relational view of knowing posits that children and people are always dependent on others to acquire skills, know-how, and knowledge and are also dependent on others' acknowledgement of their skills and knowledge in order to get recognized as knowledge-producing agents and to exercise epistemic agency. Simply put, through participation and interactions with others, children and people learn what constitutes knowing and develop skills to come to be counted as knowers themselves. What this implies is that within unjust societies where skills and knowledge are always recognized from the perspective of the dominant group, one's agency and credibility as a knower, and thus epistemic agency, can get denied and diminished, especially if one belongs to a non-dominant or a systematically marginalized group. This, gender prejudices in patriarchal societies may function to systematically diminish and erase epistemic agency of students belonging in the minoritized gender groups.

Gender prejudices may diminish epistemic agency in at least two distinct yet interrelated ways. First, epistemic agency is often erased or diminished for those who may draw on alternate ways of knowing and being such as culturally-situated or feminist practices. This is often more simply explained as sexism that refers to the valuing of men, maleness or masculinity over women, femaleness, and 
femininity (Airton, 2009; Esmonde, 2011). Burton (1995) discusses that since context, intuition, subjectivity, and collaboration are concepts often linked to femininity, they are also often diminished as having no place in the knowledge-building objective practices deemed as masculine in the field of mathematics. Sexism also intersects with race/ethnicity, culture, class and so on, like valuing of White girlhood or femininity over Black girlhood or femininity (e.g., Gholson, 2016).

Second, epistemic agency is often challenged or mocked for those who may deviate from the locally gender normative practices. This concept is often captured as genderism, which is valuing people who are seen as locally gender normative over people who are seen as non-normative. For example, valuing people with female or male bodies who look, act, and speak like women or men respectively in a particular context over non-binary gender identities.

Within the confines of math and science education, scholars have argued how nurturing students' epistemic agency influence students' relationship with the discipline, their mathematical identity, and learning (Gresalfi, Martin, Hand, \& Greeno, 2009; Miller, Manz, Russ, Stroupe, and Berland, 2018). When students' agency is denied, diminished or challenged due to sexism and genderism, students are also denied disciplinary authority and accountability to question, inquire, and argue, and the right to explore culturally and epistemically diverse viewpoints. Such denial of epistemic agency further strengthens dominant ideologies of knowing and being, resurrecting ideals of heteropatriarchy. Studies in philosophy argue that mechanisms of social bias are currently too narrowly defined (Goguen, 2016). Even though it is one of the most widely studied constructs in psychology, bias (gender or racial) and its threats is often only studied in relation to achievement, opportunities, and affect. Goguen (2016), for instance, highlights the multidimensionality of the construct to:

expand upon moral analyses of stereotyping, and to flesh out the significance of stereotype threat as a phenomenon whose impact and costs are not distributed equally across humanityeven though the phenomenon itself might be a universal human experience. But the effects of 
stereotype threat can harm members of socially subordinated groups more deeply than it can members of dominant groups. (p. xv)

In Goguen's perspective biases and stereotyping leads to a distinctive form of damage that negates epistemic, ontic, and moral status of members of socially subordinated groups. Fricker (2007), a social epistemologist, refers to this phenomenon as "epistemic injustice" and explains it as "a wrong done to someone specifically in their capacity as a knower" (p. 1).

Fricker (2007) situates epistemic injustice as distinct from injustices caused due to distributive unfairness of opportunity gaps, where not everyone gets their fair share of epistemic goods, such as information or education. Fricker argues that when injustice takes the distributive form, the goods in questions, i.e., information and educational opportunities, happen to be of epistemic characteristic, but there is nothing very distinctively epistemic about the mechanism or form of injustice itself. While injustice caused due to the limited access to educational resources or opportunities is a harm done to the minoritized sub-groups, those forms of injustice do not constitute Fricker's concept of epistemic injustice. Epistemic injustice according to Fricker constitutes harm done to people in their very capacity as knowers.

At an individual level, Fricker explains, epistemic injustice occurs when the credibility attributed to someone's capacity as a giver or producer of knowledge is diminished by prejudice of some kind. An example of this would be when a male peer ignores or mocks a female students' math idea as not efficient without justifying why he thinks so and instead focuses on a male peers' solution. Or when a teacher does not invite a Black female student to participate in a mathematics competition even though she is equally mathematically proficient as other invited students due to the teacher's general beliefs about who might perform better in a mathematically competitive environment.

At a structural level, Fricker (2007) explains, epistemic injustice occurs when harm is done to someone as a result of the insufficient shared concepts or interpretive resources owing to a restricted or 
unequal participation of certain social groups historically in the generation of those concepts and resources. Here, Fricker highlights experiences of people that are not even sufficiently shared concepts for others, especially dominant others, to make sense of because they do not operate with those concepts or not in sufficiently shared way. So, experiences of epistemic injustice, in the form of resistance or complaint, will never be recognized or even reach those forums where they can be discussed as experiences worth listening to and to be dealt with without biases. An example of this would be that a person identifying as a woman is dismissed from the job after complaining about gender discrimination in salary or promotion in a technology industry because the industry culture lacks understanding of or refuses to understand the concept of "gender discrimination in salary or promotion". Another example would be a Black girl who had suffered sexual objectification and discrimination from peers and teachers in middle-school mathematics classroom and who was earlier confident about taking advanced mathematics classes opts-out of high-school mathematics while explaining that she is not as good at math as she thought herself to be in the past.

\section{Method}

Through a systematic approach (Machi \& McEvoy, 2016), the literature from the past 30 years was examined through electronic searches including Google Scholar, Mendeley and UCl library catalogue. I used Machi \& McEvoy's six steps of literature review process to carefully identify, reduce, and synthesize the findings of the relevant studies. As a first step, the review topic was defined by reading research reviews (e.g., Else-Quest, Hyde, \& Linn, 2010; Joseph, Hailu, \& Boston, 2017; Leyva, 2017) and professional trade journals (e.g., http://hypatiaphilosophy.org/; Stanford Encyclopedia of Philosophy) as well as news and blog sites on the topic of interest: Gender Bias and Disparities in Mathematics. This allowed general understanding of the key terms, historical interpretations, turning points, current issues, debates, concerns, and future directions in relation to the topic. This initial search allowed me to refine the topic and the guiding question to ensure its clarity, answerability, conceptual 
boundedness, reasonability of assumptions, possibility of different outcomes and opinions (Wallace, 2019).

Next, I built an argumentation outline by searching and surveying the literature (steps 2-4 of Machi \& McEvoy, 2016). All articles since 1989 were considered. Following key phrases were used to search Google Scholar, Mendeley and UCl library catalogue: "gender mathematics", "gender bias mathematics", and combination of phrases using the following keywords: (negotiating, resisting, disrupting + (gender, gender nonbinary, sexual minortized, girls, female) + (stereotypes, bias, disparity, injustice) + (identity, agency, discourse) + mathematics (classrooms, after-school, maker-spaces). I also consulted the references of comprehensive literature reviews, seminal studies, news and blog items to identify articles online search might have missed. This yielded over 400 potential studies that were further scanned and skimmed for further reduction and selection of the appropriate literature. The titles and abstracts of the articles were scanned to select articles that were directly relevant to the guiding question, were empirical peer-reviewed papers constituting primary or secondary data, and took a strength-based approach. The abstract and conclusion of the articles were also scanned to answer the following questions: 1) Is the article only about uncovering gender differences and achievement gaps? 2) Is the article only about delineating inequitable experiences faced by the students? 3 ) Is the article solely in the context of science? 4) Is the article's focus solely on race? The articles with 'yes' as an answer were not selected in the final data set for review, but were used for the purposes of identifying current issues, future directions, and for framing the literature review. This filtering yielded 106 articles The remaining 106 articles were skimmed again to identify the claims of the findings and were assigned into one or more categories: 1) naturalistic responses of the students themselves when faced with inequities in the environment; 2 ) the designed interventional programs and pedagogical design of the classroom; or 3) naturalistic teacher, parental, or institutional responses to inequities. This understanding was used to identify simple and complex claims and to discover the major premises and 
arguments (step 4 of Machi \& McEvoy, 2016). The literature was largely interpreted and critiqued (steps 5-6, Machi \& McEvoy, 2016) through multiple cycles of outlining, memoing, writing, and consulting with the experts in the field.

Lastly, I consulted Hypatia: A Journal of Feminist Philosophy, Stanford Encyclopedia of Philosphy, and YouTube lectures by scholars on the topics of "epistemic injustice", "feminist social epistemology", and "feminist perspectives on power". The articles and videos on these topics were used to strengthen the conceptual framework for the current review.

\section{Individual-Level Responses}

\section{Avoiding Sites of Gender Bias}

Self-segregation into gender-homogenous peer groups is a common phenomenon among young children. Some research suggests preferring same-gender peers may be a potential response to avoid the social threats at least at the time of important life transitions (Jackson and Warin, 2000) such as when beginning primary school for the first time (Warin, 1998) and when transitioning from primary to secondary school (Jackson, 1997). Questionnaires with thirty-eight boys and girls from White working and middle class families in England during their first year of transition from primary to secondary school reveal that girls, more so than boys, tended to avoid social comparisons of their math test scores with boys and retreated in girls-only groups as a response to the increasingly competitive and aggressive behaviors of adolescent boys (Jackson and Warin, 2000). Interviews with six students further revealed that girls feared "being made fun of" irrespective of their scores: higher test scores than boys meant being called "swot" and lower scores meant being called "stupid". Perception that girls succeed in mathematics due to their efforts and not because of their intelligence is a common social bias that exists across different cultures (Francis, 2000). What Jackson and Warin highlight is how social biases, such as gendered perception of success, shape discourse and lived experience for young boys and girls in their everyday interactions. Children, thus, may be induced to structure themselves in ways that would allow 
them to avoid those biases, especially in the absence of resources that would allow willful resistance and disruption rather than avoidance. This is in line with the studies that employed situational cues and found that having opposite-sex peers (in their working-groups and in the vicinity of their class seat) negatively influenced female students' (but not males') problem solving performance and academic achievement (Inzlicht \& Ben-Zeev, 2000; Lu \& Anderson, 2015). Gender biases that exist in heterogeneous learning environments, thus, may very easily become sites of epistemic harm for girls in their capacity as knowers. As such, making gender-homogenous social groups allow girls to find safer peers and conditions in which to make sense of their mathematics performance and themselves as a knower in mathematics.

\section{Gendered Assimilation}

Some theories suggest girls often face tacit pressure to assimilate to the western patriarchal norms and values to persist in the masculinized field of mathematics (Mendick, 2006; Leder, 2004; Lim, 2008). Rather than challenge their continued marginal position in the system more directly and face adverse consequences, girls may follow dominant patriarchal definitions of femininity (arguably, White, male, cisgender, middle-class) in school and mathematics. One way in which the gendered assimilation plays out is through the acceptance of meritocratic ideology. Meritocratic ideology often makes students believe that their success largely depends on their individual ability and effort (Mendick, Allen, \& Harvey, 2015). The meritocratic myth is especially more prevalent in subjects such as mathematics that often act as gatekeeper to higher education and careers in economically privileged STEM fields (McNamee \& Miller, 2009; Seron, Silbey, Cech, \& Rubineau, 2018; Stinson, 2004). As Mendick (2006) argues, students may, therefore, choose mathematics not solely because they enjoy it but because it may allow them to feel valued in a neoliberal patriarchal society where they may otherwise not be valued; boys on the account that they are expected to and girls on the account that they are not (Brown \& Josephs, 1999). Mendick's (2006) interviews with sixth-form college students (typically 16-19 years 
old) in London illustrate how doing mathematics to feel valued creates tensions for girls making it more difficult for them to succeed as compared to boys. She writes,

Choosing maths is one way in which these students do gender, and when this is combined with the gendering of maths as masculine and the social power that attaches to the subject, it is a significant source of inequity ... maths becomes part of each student's gender identity project. (p.70)

For example, some girls in Mendick's study, who chose mathematics to prove their worth to others or themselves also, reflected what that meant for their changing relationships with their family, teachers, and friends. Lucy, who chose mathematics to seek validation of her intelligence, was also initially afraid that her male teacher might look down upon her as being a "stupid cow"- perception of what her femininity may stand for others, especially males, in a mathematics class. This changed as she started enjoying the subject for its own sake and became more careless about her teacher's (male) perceptions of her abilities. Becoming confident in mathematics also meant freeing herself of sexist perceptions of others. For another student Julie, choosing mathematics meant finding ways to sustain her old friendship with friends who were not taking mathematics. As such, girls in choosing to do mathematics were constantly negotiating sexism--conflicts about relationships and ethics specific to their feminine identities in a masculinized field.

More recently, the findings on gendered assimilation have been further complicated by bringing to fore the intersectionality of identities (e..g., Archer et al., 2012; Fordham, 1993; Lim, 2008). Studies in this line of inquiry has described how gendered assimilation also plays out by way of liberal feminism when girls from minoritized and/or working-class communities sustain their academic mathematical enterprises by aligning themselves to White feminine values at the cost of their authentic gender expressions. For instance, often African-American girls' display of their culturally feminine expressions is deemed "loud", and sits in opposition to the unassumingness and unassertiveness that is often expected 
of females. Loudness is often read by the teachers as a defiant behavior (Lei, 2003; Morris, 2007; Wun, 2016). Fordham (1993) conceptualized the notion of "invisible Black female" in her study of Black high school students' experiences at a diverse magnet school. Fordham found that Black girls, even those academically successful and competent, make deliberate efforts to imitate characteristically male or White female ways of being and to act as silent invisible "ghosts/phantoms." Erasing or hiding their genuine Black feminine identities and appropriating White middle-class femaleness in their behaviors becomes a strategic move to seek social legitimacy and position them away from their cultural gender identity.

More recently, within the studies of mathematics classrooms, Lim (2008) found a similar phenomenon as she explored how sixth-grade female students seek support for their mathematical positions by actively constructing their self-identity in relation to patriarchal patterns of White, middleclass values. These social constructions were intricately linked to students' social identities (race and class) and influenced their choices and decisions in mathematics learning (also see Archer et al., 2012). Through interviews, Lim de-constructed how young adolescent girls in the advanced mathematics class experienced the same learning environment differently. Jessica, a White middle-class girl, articulated a confident identity as a mathematics student and took pride in her group of high-achieving close friends from similar cultural and class backgrounds, often referred by others as "smarties". Jessica also depicted a strong sense of conformity towards school practices, meritocracy ideology, and thrived as an ideal neoliberal subject (Mendick, 2006). Her identity and values seemed as shaped by and in harmony with each of her intersecting social worlds-family, social clique, mathematics classroom, and her relationship with the teacher. In contrast, Stella, an African American student from a working-class background, also a top-performing student in the same advanced math class, reflected a conflicted understanding of herself and of her mathematics classroom. Being part of the social worlds that often were in stark contrast to each other, Stella's perceptions of her own experiences seemed at odds with 
what constituted her collective self-family and friends. Even though she personally liked her teacher, her close friends of varying achievement levels considered the teacher mean who cared less about helping (struggling) students learn math. In discussing this experience, Stella could not reveal a clear perception of her teacher, being conflicted between her own and her close friends' experiences. As a result, similar to Julie in Mendick's study, Stella resorted to the performative ignorance through "I don't know" responses during the interview about her mathematics experiences. Stella reflected how she consciously changed her way of talking at school having been unfairly accused of being "very loud" and distance herself from her close friends to conform to the classroom practices. Even though Stella was one of the highest performing students in the class, she did not consider herself to be the top student.

Past studies have consistently revealed how African American youth tend to engage in forms of impression management to control their authentic actions and behaviors when facing racial discrimination through role-flexing and hypervigilance to appear nonthreatening and non-defiant, such as speaking softly, using care not to express overt anger, and instead using humor, playfulness, or class clowning (Franklin \& Boyd-Franklin, 2000; Steward et al., 1998). It has been further determined that while the impression management strategies may help with minoritized students' psychological adjustment in unjust environments, they occur at the cost to their academic outcomes, persistence, and most of all dignity. As such, another response to liberal feminism has been cultural socialization, including the internalization of messages regarding the importance of religion/spirituality and racial pride, cultural identity formation, and preparation for biased experiences, as important in the development of a healthy sense of self in relation to their own community, especially among Black adolescent boys (Spencer, Fegley and Harpalani, 2003). Neblett et al. (2006) also found that racial socialization was related to various academic achievement outcomes, including academic curiosity, engagement and task persistence in classrooms, and self-reported grades. The finding was not 
replicated among girls and was not investigated in the context of gender bias, suggesting the need to investigate other forms of support.

\section{Resistance and Mitigation}

In contrast to the assimilative yielding responses, a subset of literature in gender and mathematics sheds light on girls' resistive responses to masculinity in mathematics. This literature highlights the ways in which individuals themselves actively negotiate, resist, and mitigate discourses of sexism and genderism in order to forge a space for themselves in the system and persist.

\section{Resisting Masculine Competitiveness As Mathematical Brilliance}

This category emerged from the review of studies that have examined experiences of girls in relation to an institutional practice of ability-grouping. By studying females in the mathematically highachieving classrooms in middle- and high-school and women pursuing degrees in college mathematics, scholars have attempted to understand students' responses to the masculine culture in mathematics. Land (2003) in a study of highly able, middle-class girls and boys found that although both appear to be equally confident, boys maintain their confidence through competitiveness with each other whilst girls maintain theirs through feedback from their teachers and collaborative opportunities with peers (Solomon, Lawson, \& Croft, 2011). Leyva (2016) has found various strategies employed by women of color in undergraduate math courses: staying humble, not over comparing their performance with others, and not "overshoot[ing]" in mathematics classes. Similarly, McCullough (2015) found that young girls engaged in several practices to counter the gendered expectations of their teachers, their concern with their reputations and the ongoing harassment by the boys through willful non-participation in classrooms and by controlling the narrative of their identity. These practices, however, were not always directed against the bias they were facing, but to avoid the aftermath of it.

More specifically, Bartholomew's (2000) case study investigated how notions of mathematical brilliance gets constructed as a result of ability-grouping practices in schools and its implications for 
students' self-perceptions as learners. Drawing on data from six schools in year 8 onwards, she argues that "combining success in the top set environment in the UK [similar to honors or accelerated classes in the US] with an acceptable feminine identity is likely to be a much more complex matter" because of the emphasis on competitiveness rather than on deeply understanding concepts. Girls who were interviewed expressed frustration about the focus on getting quick and correct answers instead of understanding the concepts deeply. Boaler (1997) has also discussed how "high ability girls are, for some reason, more likely to desire understanding and become disaffected when they cannot attain it" ( $p$. 179). Instead of disengagement, Bartholomew finds a response of resistance in the interviews with highachieving female students. By following Tania's reflection of her practices from year 10 to year 11 through surveys and interviews, the author highlights how Tania self-constructed her ideas about what mathematical success meant for her. It meant recognizing that she no longer wanted to compete with the group of boys who dominated her top set class- "like the ones people feel threatened by". Once realizing that she was getting better scores than those she thought were clever, she stopped following their plug-and-solve methods to simply get quick answers. Instead, she determined her own ways of problem solving by reflecting, building on, and connecting with her past knowledge.

Rodd \& Bartholomew (2006) found similar narratives of intentional resistance in female undergraduate students' explanations. While women in a traditionally perceived masculine field of mathematics considered themselves "special", they also exemplified a form of "invisibility" in their narratives that authors describe as "female fierce modesty": such as not publicly sharing that they found the subject easy to avoid discouraging others who may have found it hard or waiting for others to finish before sharing solutions in the class. Authors deem students' feeling of "specialness" as "defensive investments in their particular ways of participating" rather than an expression of masculinity. Further, female students' invisibility in class participation was interpreted by the authors as a controlled quiet response to resist the patriarchal model of brilliance as a competitive display of interactions. This 
intentional invisibility, thus, is not the same as epistemic silencing. In fact, it is quite the opposite. It is the modern women's way of challenging the dominant practices in the field that has kept many subgroups from entering or persisting in it.

\section{Resisting Femininity and Mathematical-identity Divide}

Patriarchy also constructs a false binary between feminine and mathematical identity whereby it is believed that feminine characteristics and gender expressions are not aligned with traits of people who do mathematics. Through interviews with women in mathematics at university-level, studies examine how they negotiate or resist this divide. For example, Solomon, Radovic, and Black (2015; also see Solomon, 2012) explores Roz's trajectory of becoming a mathematician through interviews at different time points in her journey as a college student. Roz is a mature woman who had returned to do her undergraduate, masters, and $\mathrm{PhD}$ in mathematics after several years of motherhood. The authors illustrate how she over time negotiates her fear of "being found out", of potential failure as a mature woman in mathematics. More interestingly, the article presents the story of her "becoming" and learning to resist the divide between her feminine and mathematician identity that in the past had led her to produce contradictory narratives about herself as feeding a "male brain" in a female body. But, as a postdoctoral scholar, Roz was becoming more resistant towards this divide and instead beginning to produce a "new hybridized identity" (p. 63) of her doing mathematics while enacting traditional femininity in her choice of dresses. Bullock (2018) refers to this discursive and performative act as "an act of resistance to the figure hiding of mathematics' masculine sensibility" ( $p .126)$. The authors further argue that this contradiction was not resolved by her settling for a loss on either side of her identity performance, "rather both are retained in the production of what she perceives to be a new way of being a mathematical person" (p. 63).

Some theories also argue that gaining role models who defy false gender dichotomies and set new norms, opens up possibility for others to also resist the status-quo rather than conform to it, thus in 
part propelling a social change through "undoing gender" (Butler, 2004; Deutsch, 2007). For instance, Shaw (2001) examines individual acts of leisure as sites of resistance, such as a girl joining a boys hockey team or a mother taking leisure time. She argues that these acts of resistance are not bound to that one individual's achievement of identity, but can expand into collective movements. Other girls and women may see possibilities for them too and may inspire themselves to follow that path when witnessing others like them do it.

\section{Resisting Homogenous Identities}

Jorgenson (2002) examined the types of gender identities women claim for themselves in a context where the popular image of the profession continues to be strongly associated with masculinity. In seeking to position themselves as qualified professionals, they demonstrate multifaceted selfidentifications and manage multiple dynamic identities in relation to any given context. Five dimensions emerged as particularly salient in their personal accounts. Participants positioned themselves as intellectually and emotionally career identified, organizationally adept in coping with male-dominated workplace cultures, nonfeminist in the sense that they were reluctant to organize as women, good mothers pained by conflicts between work and family, and singular selves resistant to being perceived as members of a homogenous group. These findings speak to the contradictory nature of women's professional identities and suggest that women position themselves in relation to their gender differently in different contexts.

\section{Summarizing Individual-Level Responses}

Acceptance of meritocratic ideology or liberal feminism may allow access to the social power attached to mathematics but it occurs at the cost of students' complex cultural and gender identities. Assimilative strategies may make it especially difficult for girls with minoritized racial or cultural identities to accept their ethnic/feminine selfhood in conjunction with their mathematical self. While these assimilation practices may benefit White middle-class femininity in relation to the normalized 
White middle-class patriarchal culture, they disadvantage girls from working-class, minoritized backgrounds. Assimilation practices also work to reproduce and sustain gendered oppression and inequality. Dismissing the dynamic, feminine, and collective self-hoods of girls on accounts of conformity to the deep-seated patriarchal norms in mathematics education, diminishes and erases the capacities of girls as knowers and doers of mathematics in their own right. Epistemic harm occurs when girls stop bringing their whole selves to their mathematics learning and instead have to alienate their mathematical self from their "other" self. Over time, it may result in girls' diminished interest in the subject, feeling conflicted in their life choices or dropping out to instead pursue fields or activities where they have more freedom to embrace their whole selves (Steffens, Jelenec, Noack, 2010). To summarize, ideological/ social beliefs and norms of what it means to do mathematics while being a Black or a Brown girl subconsciously takes the form of gendered assimilation in learners' everyday interactions and behaviors. In the absence of structured institutional response towards legitimizing a girlhood that may look and feel different than what dominant ideologies of patriarchy demand, the assimilative behaviors in micro interactions acts as the site of epistemic harm.

Furthermore, in light of the literature on resistance and mitigation, the question arises: under what conditions do girls/women disengage in mathematics learning (e.g., Boaler, 1997) and when do they resist when confronting the competitive masculine culture and femininity divide in their mathematical identities? An interesting knot common among the participants of aforementioned studies who resisted competition was that they all had reported having developed positive conceptions of gender in mathematics. This developed as they realized their competence in relation to boys. These were all women in their senior years, college, or professional fields and have had ample opportunities to probably observe competent women as well as incompetent men in mathematics. In drawing implications for these findings for elementary and middle-school children, it is not clear, if younger girls would have had enough opportunities and experiences to yet develop a positive sense of what it means 
to be successful in mathematics like many of the high-school and college women in the reviewed studies. As Boaler (1997) points out, under such conditions then it is not solely the responsibility of the students, but instead it becomes a function of classroom practices and norms that focuses on understanding over getting quick answers and values explaining and questioning over telling. Lacking these norms of mathematical practices that challenge general beliefs of what it means to do mathematics, there lurks epistemic harm wherein girls begin to falsely equate their gender expressions and what others might deem "slowness" with mathematical deficiency thereby disengaging early on in their mathematical journeys.

Moreover, while individual resistance to persist in the face of everyday gender-biases may counter the epistemic harm at an individual level, it does little to change the structures that perpetuate masculinity in mathematics. So while some girls with greater access to social capital (White, middleclass) may find ways to push through binary and masculine thinking, students with marginalized histories and backgrounds may not. The opportunities for attaining epistemic justice, thus, may then lie in understanding the ecological connections and developing support structures that can fill the unique needs of race and gender minoritized girls in mathematics.

\section{Institutional Responses}

\section{Single-sex Learning Environments}

One structural response to the gendered threats faced by girls has been to provide children with single-sex mathematics education. Educators and policy-makers advocating for single-sex learning environments often justify this move as providing children the ideal (assumed) conditions that matches their gender preferences and ways of learning, while minimizing/avoiding the biases, distractions, and disciplinary issues that trickle in mixed-sex settings. I review this research and group it in two strands: single-sex after-school programs and single-sex mathematics classrooms and groups.

\section{Single-sex Extracurricular Programs}


Gender-equity community leaders and scholars have advocated for single-sex after-school math, science, and STEM programs that actively avoid sites of bias to first do the confidence-building work in a homogenous setting while catering to the needs of the unique sub-group of students. Programs range in their focus, mission, and target population. Some programs offer a space designed specifically for girls to explore hands-on STEM activities, learn about STEM careers, and get inspired by women role models and mentors in STEM (e.g., GO-GIRL targeting potentially talented seventh-grade girls from minoritized backgrounds). These programs are often short and occur during summer or winter break with an option to return the next break. After-school programs also occur during school-term often at the school-site providing year-long weekly classes (e.g., "The Sisters in Science" program (SISP) targeting fourth-grade female students at two Philadelphia elementary schools). While after-school programs may differ considerably, still a common feature among them is the integration of design-based research and reform-based mathematics activities focusing on conceptual understanding, questioning, and mixedability group work (Cohen \& Lotan, 2014). Instructors and mentors in the programs also often hold high expectations for their students, and, in general, increase the presence of same-sex (Bowe, Desjardins, Clarkson, \& Lawrenz, 2015; Vrooman, 2009) and same-race (Klopfenstein, 2005) role models and peer mentors.

Studies examining the effectiveness of single-sex after-school programs using surveys, assessments, observations, and interviews consistently conclude that participation in a good quality program in general increase girls' confidence in mathematics and improves their mathematical skills and achievement (Campbell, 1995; Hammrich, 1997; Hanson, 2009; Reid \& Roberts, 2006). The success of single-sex after-school programs depends on the design and purpose of the program activities (Hammrich, 1997), the fit between the program and the community they serve (Kusimo, Carter, \& Keyes, 1999), and the extent to which they provide a safe environment for girls to take up challenges and risks in their learning (Morrow \& Schowengerdt, 2008). For instance, Kusimo, Carter, \& Keyes (1999) 
found that while the rural site of the four-year long Voices program was able to successfully meet the needs of the participants, it almost failed in the urban site. The rural site was facilitated by two African American women who were county "insiders" and provided a natural bridge between the program, community, and the schools. The community connection that was lacking in the urban program resulted in a failure to understand the unique needs of the sixth-grade urban girls it was serving. Similarly, the Go-Girl program that provides hands-on STEM activities to participants reported gains in girls' mathematical skills and confidence (Reid \& Roberts, 2006). In contrast to the Go-Girl program, SISP program activities that integrate real-life community-based activities and also engage participants in direct conversations about gender biases reported gains in girls' attitudes about the potential of mathematics as a possible career path (found null in the Go-Girl program) in addition to the gains in skills and confidence (Hammrich, 1997).

Despite consistently being shown to increase girls' confidence and outlook towards mathematics, studies of single-sex programs fall short on examining to what extent these changes persist, particulary when girls engage in mixed-gender mathematics settings? Some scholars argue that the single-sex programs, as yet, do little to rupture existing patriarchy in the society. Morrow and Schowengerdt (2008), for instance, argue that after-school programs, in addition to the focus on mathematical activities, must also find resources and deliberate activities to engage girls in practices that would disrupt the settled patriarchal norms, such as aversion to risk-taking by females, to instead open up spaces where they can explore, take risks, make mistakes, and learn. In essence, it is not clear whether avoiding the site of gender-bias as an underlying strategy to first build girls' mathematical confidence and interest in single-sex settings in fact allow girls to persist in mathematics or not.

\section{Single-sex Mathematics Classrooms and Groupings}

Single-sex education has also been used within schools to teach girls and boys in separate classrooms as a way to arguably address their unique interest and learning styles, to minimize 
distractions and disciplinary issues, and to increase scores on high-stakes achievement tests (Chouinard, Vezeau, and Bouffard, 2008; DeBare, 2004; Meyer, 2008). The results on the effectiveness of single-sex classrooms, however, have remained mixed (e.g., Bofah \& Hannula, 2016; Bowe, Desjardins, Covington Clarkson, \& Lawrenz, 2017; Kombe, Che, Carter, \& Bridges, 2016; Pahlke, Hyde, \& Allison, 2014; Park, Behrman, \& Choi, 2018). There has been a great deal of confusion in the literature regarding how to isolate and associate changes in achievement to single-sex education alone. Pahlke, Hyde, \& Allison (2014) addressed this issue in their meta review of 184 studies comparing K-12 single-sex and coeducational settings including 1.6 million students from 21 nations. They differentiated controlled from the uncontrolled studies to make sense of the findings and did not consistently find single-sex classrooms to have significantly large benefits over co-educational classrooms. As such, in the controlled studies (that used random assignment or controlled for preexisting differences), the performance and attitudes of single-sex and coeducational students in general were not significantly different for both boys and girls. However, the uncontrolled studies often reported single-sex setting to be more effective than co-educational. The authors argue that it was not just the single-sex componenet but a combination of students' prior experiences, pedagogy, curriculum, and instructional resources that contributed towards gains in achievement and attitude in the uncontrolled studies.

Moreover, previous studies in single-sex literature have almost exclusively focused on examining performance, attitudes, and self-concept. Very few studies have investigated changes in students' own gender stereotypes in mathematics as a result of single-sex education. Pahlke, Hyde, \& Allison (2014) found only eight controlled studies out of total 184 that had examined girls' gender stereotypes and even fewer studies of boys' gender stereotypes with varying measures of the construct. Some scholars worry that single-sex education may increase students' gender stereotypes, further aggravating the problem rather than solving it. Scholars have only begun to investigate questions of stereotypes and classroom climate. For example, results from a recent study by Kombe, Che, \& Bridges (2019) in three 
middle schools in the southeast U.S. indicate that participation in single-sex classes did not increase, if not decrease, the gendered perception of mathematics as a domain. Studies examining classroom climate have indicated that girls report feeling more empowered to raise their voices and share their ideas arguably due to diminishing competitiveness and decreasing fear of being mocked by the boys (e.g., Baker, 2002). Brown \& Ronau (2012), in contrast, find no differences in the reported classroom climate of single and mixed-sex classes.

The issue is further complicated by the fact that racial, cultural, classed, and ability-based ideologies remain present in single-sex (but otherwise diverse) classrooms. If a school is not demographically diverse, minoritized students in single-sex settings may find fewer opportunities for solidarity and connection. Single-sex literature has not yet considered the social ecology of classrooms and schools in their examination. To some extent this gap has been addressed by the literature investigating single-sex grouping in co-educational classrooms shedding light on complex and multiple identities that students co-perform when working together. For instance, Esmonde, Brodie, Dookie, \& Takeuchi (2009) investigate group work in a heterogeneous urban high school mathematics classroom and found interactional style, mathematical understanding, friendships and relationships as the most influential factors for students in how they describe their interactions in groups. The authors also highlight the gendered nature of these factors at the intersection of race. For instance, while White girls described all-girls groups did not work well for them because girls in all-girls groups became competent and it was hard to take up leadership roles. They described two boys and two girls group working better for them. Whereas, students from racially marginalized groups preferred gender-homogenous groups (i.e., all girls) by explaining that they could take up more leadership roles with all girls rather than becoming passive when working with boys in the group (see also, Bear \& Woolley, 2011). In contrast, Valera \& Takeuchi (2018) found no clear connection between gender and leadership roles. Instead, they 
determined it was students' positive versus negative mathematical identities that shaped their leadership roles, even though gender played a role in other ways in structuring group dynamics.

\section{Collaborative Learning and Complex Instruction}

Coming out of the tradition of sociocultural theories of learning, some scholars argue that another response to threats of implicit biases is to help children develop skills that create positive crossgender work-partnerships and experiences (Boaler \& Greeno, 2000, Langer-Osuna, 2016, 2017, Esmonde, 2009; Sengupta-Irving, 2009). There has been an explicit focus on discourse, activities, tasks, tools, materials, norms, and teacher moves in this line of thought. With reform-based mathematics, educators and researchers have also advocated for small-group collaborative learning in mathematics (Cohen, 1994; Slavin, 1996; Webb \& Palincsar, 1996). There exists a strong research base that argues that when students have opportunities to share, reason, argue, and revise their thinking together, whether as a whole-class or in small-groups, then they have more opportunities to construct positive mathematical identities of themselves and each other (Boaler \& Staples, 2008; Hufferd-Ackles, Fuson, \& Sherin, 2004; Sengupta-Irving, 2014). Implementing norms and responsibilities in diverse classrooms that foster positive experiences with peers of all genders, such as taking responsibility for each other's' learning and valuing effort over ability, may help children develop relational equity, multidimensional views of brilliance and of how different people learn together (Boaler, 2008; Boaler \& Staples, 2008). Furthermore, Cohen \& Lotan (2014) has elaborated teachers' role in explicitly attending to status hierarchies by publicly assigning competence and raising status of students who may get positioned with low-status among peers (see also Gibbs, 2003 on the role of pedagogy for equity). Rather than placing responsibility for negotiating inequitable experiences on students or segregating students so they can avoid those experiences, this line of inquiry presses for school and classroom-level structures to instead change in ways that can support each and every student. 
Scholars have also explored how small-group student interactions may become semi-structured spaces providing opportunities for students to resist and disrupt localized events of gender bias. For instance, Esmonde and Langer-Osuna (2013) highlights the role of off-task interactions in mathematics classrooms. It was "found that off-task interactions-which drew on discourses of romance and friendship, which were racialized and gendered-regulated group members' participation in small group mathematics discussions. Students' off-task conversations functioned to resist domination by a peer with high academic status, enabling shared intellectual contributions to the mathematics discussion. Off-task conversations supported shared participation in large part because two students who were relatively marginalized from engagement in the mathematics utilized off-task conversations to position themselves with social power, which functioned to resist the third student who had been dominating the mathematical work. That is, off-task interactions offered students the ability to position themselves with relatively greater power than was available through on-task interactions. While on-task interactions drew from school math discourses, off-task interactions primarily drew from discourses of youth popular culture, friendship, and romance. Students utilized these discourses as positional resources, enabling new pathways into the collaboration."

Langer-Osuna (2014) examines the role of the teacher in supporting a learner's cultural identity and leveraging it towards his mathematical engagement. This finding caters to the past literature that finds how African-American male students often face a specific form of gender inequality and racial bias. Male students continue to be perceived as lower in academic achievement as compared to African American females and males of other races and more in need of special education services (Noguera, 2003b; Skiba et al., 2002; Jencks \& Phillips, 1998; Osborne, 1999; Steele, 1997; Bay Area School Reform Collaborative, 2001; Gilliam, 2005; Neal, McCray, Webb-Johnson, \& Bridgest, 2003; Thomas \& Stevenson, 2009; Stinson, 2013). African American males are also generally viewed as possessing characteristics incongruent with academic success (e.g., laziness), valuing athletics over academic 
accomplishments, and having a propensity toward aggression and violence (Hall, 2001; Wood et al., 2007). Spencer, Fegley, Harpalani, \& Seaton (2004) have argued that "for male adolescents in high-risk contexts, hypermasculinity may be a way of symbolizing gender identity achievement." (p.240). LangerOsuna finds that affordances of autonomy provided by the teacher an African-American male student named Terrance allowed him to leverage his out-of-school positional identities, which included a sense of toughness and rebellion that he had picked up from experiences in neighborhood fights, in ways that supported his development as a learner. Since the classroom's activity focused on the New Tech model, affordances of autonomy was in part a consequence of how the teacher re-positioned Terrence's cultural identity as a professional knowledge worker in the corporate business world (which the author explains is at the same time problematic).

Gholson (2016) have argued that positioning mathematics as a field of choice for children instead of as a reflection of ability or belonging may better disrupt "representational politics" that is pushing for more girls in STEM without centering the experiences of girls, racially minoritized learners, and I will add, gender nonconforming youth. Sengupta-Irving \& Vossoughi (2019), additionally, argue that to challenge representational and respectability politics, organizing for "dignity may better account for the complexity of girls' experiences and serve as a resource for research, pedagogy and design". The authors invite scholars to think about the design of learning spaces that not only center sociocultural contexts but also consider sociopolitical and ethical dimensions of learning such as rationale for mathematics learning, challenging notions of individual gain, problematizing what counts as mathematics, insisting on values such as creative joy, ingenuity, and humanity.

\section{Gender-Complex Pedagogy to Disrupt Gender Bias}

The fourth line of inquiry in gender research in mathematics has 1) considered interventions that challenge and disrupt gender biases of teachers, teacher educators, parents, and children more proactively; 2) examined ecological responses in how concerned actors (parents, teachers, students) 
may come together to demand more equitable practices; and 3) investigated the role of the state and national policies in legitimizing and providing resources to the grassroots efforts. The interventions are positioned as systemic responses to make sense of gender fluidity with children and to increase awareness of the mechanisms and harms perpetrated by gender bias with teachers and parents. Although most of the studies described in this section have been studied in the context of adults and institutions (not directly with children in the classrooms) and many are not specific to mathematics education, the findings nevertheless offer tools and resources that may guide cultural change in society towards epistemic justice for gender(race) minoritized students. Scholars have further pointed out that the role of educators and of the design of the learning spaces that deliberately counter gender binary thinking and biases. Rands (2009) conceptualized "gender-complex education" to challenge gender-blind pedagogy that continues to exist in many classrooms. According to Rands, gender-complex education: takes into consideration the complex sets of privilege and oppression that students and teachers experience based on their gender categories, gender expressions, and the gender attributions others make of them. Gender-complex educators are aware of the ways in which the gender oppression matrix and heterosexism work in tandem to privilege certain groups of people and oppress others and take action to challenge the gender oppression matrix and heterosexism. The gender complex teacher does not expect children to fit into a dichotomous classification of gender. Gender categories are acknowledged as fluid. Gender-complex teachers work with students to analyze at the micro level the ways in which gender is constantly being socially constructed in the classroom as well as macro-level influences on this process. Moving beyond analysis, teachers and students take reflective action to reconstruct gender in ways that are more equitable within the classroom and beyond. (pp. 426-427)

In the above conceptualization, Rands specifically calls for connecting instruction and curricula, arguably the meso-level structures, with both micro-level constructions of gender in student-interactions and 
macro-level hierarchies of sexism and genderism. This call, directly or indirectly, has been taken up by several scholars in designing the gender-complex instructional materials and delineating how educators do this work in their classrooms. In the sub-sections below, I follow Rands's (2009) three levels of imagining gender-complex and consider how literature has advanced research in each of those levels: transforming ourselves, transforming teachers, and transforming students.

\section{Transforming Ourselves - Teacher Educators and Researchers}

Rands (2009) reason that since many teacher educators, and I add researchers, have themselves experienced gender socialization and/or gender-blind schooling growing up, the mechanisms of gender bias become so normalized that we may inadvertently fail to consider gender in complex ways: dynamic, fluid, and non-binary. Therefore, it is not enough to simply be aware of oppression. It requires stepping outside of the comfort zone and challenging the hierarchies of oppression (Kumashiro, 2002).

Pennington et al., (2012), for example, used critical autoethnographic self-study to examine their own dispositions as teacher educators toward their preservice teachers through a social justice lens. Over two years, they first publicly acknowledged among themselves their dispositions towards their students, engaged in its critique, and then together worked through some of their problematic dispositions to develop newer ways to approach teacher education and pre-service teacher-students. Authors identify that in revisiting their histories and addressing their own biased dispositions towards their students empowered them to be in a better place to later reposition their students in equitable ways and confront issues of race, gender, class, language in their classrooms.

In a similar vein, Strom, Abi-hanna, Abrams, Dacey, \& Dauplaise (2014), explored how they-a group of doctoral students and a professor--came together as a self-study group (see also Taylor et al., 2018). Through writing and dialogue, they experienced "becoming" agents of change and gave meaning to their feminine identity within the multi-layered hierarchies of power. The authors (doctoral students and a researcher) reflect how through self-study they found "opportunities to break away from our 
individual static identities and to collectively become a new 'assemblage' that produced new ways of thinking and looking at the world" (p.32). This then allowed them to reconsider their roles as educational researchers, their past experiences as mathematics teachers, and their place in the hierarchy of the educational system. Authors recount how they were later able to "courageously negotiate more feminist, egalitarian, and power-conscious teaching practices with their students", bring about "democratic methods and self-study to her [their] first under-graduate teaching experience", and emphasize "the importance of both shared power and privileging personal knowledge" (p. 40).

VIDS (Video Interventions for Diversity in STEM), which are short videos that expose participants (18-68 years of age, including both men and women) to empirical findings from published gender bias research, have also been found to be effective. Moss-Racusin, Pietri, Hennes, Dovidio, Brescoll, Roussos, \& Handelsman (2018) found that VIDS were effective in generating enough anger and empathy in participants towards gender disparities that moved them to express intentions of engaging in behaviors that would promote gender parity and positive attitudes toward women in STEM. Furthermore, studies have determined that VIDS that confront participants with direct evidence of gender bias is more effective than confrontation without concrete direct evidence of bias. For instance, participants in Parker, Monteith, Moss-Racusin, \& Van Camp's (2018) study were confronted with gender bias with evidence that they evaluated a female applicant for a lab manager position negatively, which would have resulted in her not being hired, and that their evaluations were more negative than an otherwise identical applicant who was male. Experiment found that this confrontation activated greater guilt and, in turn, concern about expressing and regulating gender bias in the future, relative to participants who were confronted about gender bias but without concrete direct evidence of bias. Participants were 188 Introductory Psychology students at a large Midwestern University who received course credit. While these interventions have not directly been done with teacher educators or scholars of mathematics 
education, there seems possibility to apply them in these new contexts (including with teachers and parents) to study their potential in problematizing our own thinking about gender in mathematics

\section{Transforming Teachers}

Helping pre-service and in-service teachers address their gender biases through professional development activities has been considered one of the most critical areas of research for developing inclusive learning environments. Drawing on McIntosh's (1990) work on White privilege, Kathleen Rands (2009) describe helping teachers recognize the gender privilege as a starting point for discussing gender oppression. Activities where teachers complete the sentences "Men can count on ..." and "Nontransgender people can count on. ..." and pass the sheets around for everyone to add examples and read examples added by others have been effective in teachers recognizing gender privilege in relation to other race, class, linguistic privileges. Rands describe the second step as helping teachers notice and challenge their own blind spots in how gender is enacted in their classrooms in relation to these privileges while also restructuring and reshaping their narratives. Rands provide a following list of sample questions in which teachers can be engaged in either self-study or teacher-noticing-activities:

Which aspects of dress, speech, and behavior do I interpret as expressing gender? What gendered meanings do I attribute to these? In interactions among students or between students and the teacher, what gender attributions do different people seem to be making? How do students and teachers communicate gender expectations? In what ways do students conform to or contest these expectations? In what ways do different students benefit from these various gender attributions and expectations? How are students limited by them? What roles do race, language background, form of mobility, and other dimensions play in all of this? (pp. 428)

Engaging teachers in self-study and noticing activities is in line with what Meyer \& Leonardi (2018) describe as "pedagogies of exposure" and "culture of conversation". Through self-study, teachers may get exposed to seeing gender as a fluid construct and accept ways in which children may express this 
gender fluidity while engaging in "courageous conversations" (Singleton, 2005) involving difficult critical self-reflections. This could come through personal experiences and contact with trans children and their families or through self-study and VIDS in pre-service and in-service teacher training (Bailey, Scantlebury, \& Johnson, 1999; Scantlebury, 1995; Scantlebury et al., 1996; Wilcox, Watson, and Paterson, 2004). For example, Weber and Mitchell (2000), in their self-study, examine ways in which perceptions about dressing influences gender stereotypes. Brown, Wiggins, and Secord (2008) have even advocated for exploring how preservice teachers' religious dogma might impact their gendered expectations of students. Rands (2009) offer the use Forum Theatre in teacher training to work through alternative ways to react as teachers in situations where students face gender oppressions. Generally speaking, self-study may allow teachers to reconstruct gender in ways so children and their ways of being are recognized and mobilized. Within this frame, teachers begin to recognize that there are different ways in which a child can be a boy, a girl, a trans girl, a transboy, or a child who is still exploring her gender identity. Children can like unicorns while being sporty. They can enjoy mathematics while preferring pink and sparkles. They may play with blocks while preferring social connections and being kind. They may engage in mathematical and spatial thinking through sewing and crafting. And most importantly, in an ideal world, these different ways of being will not be able to predict the gender of the child.

More recent literature on self-study in the context of gender in education has continued to find promising potential in helping teachers confront their own biases (Goodell \& Parker, 2001; Taylor \& Coi, 2014). Studies in this realm have also highlighted challenges involved in teachers doing this difficult work while facing limitations of the educational structures. For example, James (2008) reminds us of the importance of considering context when thinking about teacher training for equity. Recognizing the importance of face to face interactions and knowing one's students, James describes some of the 
challenges of online teaching where the identity markers of students are not clear and interaction time with students limited.

\section{Transforming Students - Making Sense Of Gender In Mathematics With Students}

Shared spaces that allow children and youth to make sense of gender and power in everyday practices as well as in mathematics allow them opportunities for new meaning-making, knowledge production, and to become active learning agents and producers of their own narratives and identities. The research in this line of inquiry focuses more rigorously on the design of lessons, materials, and classroom norms that would help students disrupt gender hierarchies in mathematics classrooms and out-of-school spaces (Rands, McDonald, \& Clapp, 2013; Sheldon, 2019). Rands, McDonald, \& Clapp (2013) describe it as "Landscaping Classrooms toward Queer Utopias". Rands (2009) refer to it as "Mathematical Inqu[ee]ry" that is more than and beyond a simple inclusion of queer students. Though Rands (2009) has focused specifically on elementary classrooms and queer students, the tenets are applicable to wide range of K-12 classrooms and to issues of gender in general. Queer theories allow for children and youth to be seen as not fixed but as having multiple intersectional identities that are still in the process of "constant reconstitution through discursive practices" (p. 183).

In the article, Rands (2009) provide examples of mathematical activities that would allow adding queer to culturally relevant mathematics teaching, critical mathematics literacy, critical race theory, and feminist perspectives on elementary mathematics education. One of the activities include fifth-grade students mathematically exploring the economical and financial implications of marriage laws that allow straight couples, but not same-sex couples, to legally marry. In this activity, students would also have opportunities to use feminist lens to think about how gender wage-gaps would make average incomes for lesbian couples, gay male couples, and heterosexual couples to differ. Other examples include thirdgraders using mathematics/proportional analysis to question the representation in the library's collection of books and fourth-graders analyzing representation in newspapers. Similarly, teachers in 
Outi Ylitapio-Mäntylä's study (2009) reflected how by questioning and bringing factual learning into classroom activities, students inquired about families, dressing-up, different ways of being boys and girls, as well as evidences that boys and girls perform equally well in sports, home economics, being caring, and so on. Thus, a simultaneous focus is also on undoing long-standing associations between masculinity, objectivity, and mathematics to reshape perception of mathematics as simultaneously intuitive, collaborative, emotional, subjective, and creative (Brickhouse, 2001; Gilbert, 2001; Meyer, 1998).

Studies and designs of maker-spaces have also explicitly disrupted masculinity in STEM by highlighting the role of artefacts and materials in meaningfully mobilizing non-normative and diverse conceptions of mathematics and STEM. Buchholz, Shively, Peppler, \& Wohlwend (2014) found that the ways in which the use of materials that are rooted in histories of gendered practices, such as textiling, weaving, sewing, and crafting, in electronic projects influenced how a mixed-sex dyad worked together. Referring to these materials as "e-textiles", the authors illustrate how a pre-activity to the main electronic task allowed participants to first tinker with the crafting and textiling materials. This paved way for the girl in the dyad to maintain her leadership/contributorship role, and access and control over the materials. This access and control over materials also gave her opportunities to bring forth her textiling expertise to merge with her electronics decisions. This occurred while sustaining boy's engagement and expert contributions in their partnership. Similar patterns of practices were found in other mixed-sex dyads that were observed. STEM maker spaces most often include traditional materials (legos, robots, etc.) arguably deemed masculine. Additionally, boys largely controlling the materials and the activity has been found to be a pattern of inequity in co-educational STEM spaces. Through analysing mediated actions of youth with the materials within e-textiling project, the study displays "how girls gained and maintained access to electronics equipment and controlled engineering decisions 
through shared yet unspoken anticipated identities for female crafters embedded in sewing tools and gendered histories of crafting practices" (p. 293).

As such, drawing on Nelson (1999), Rands (2009) contend that mathematical inqu[ee]ry requires more than reformed mathematics where students share and explain their mathematical thinking, devise problem-solving strategies, and discern mathematical relationships and solutions (Carpenter et al. 1999; Hiebert et al. 1997; Whiteneck and Yackel 2002). It also requires pedagogical practices that go beyond holding high expectations of all students, building on cultural knowledge of students, situating collaborative learning practices, and influencing positive identities in math (Battery, 2013; Wood, Kaplan, \& McLoyd, 2007; Cohen \& Lotan, 2014; Boaler \& Staples, 2008; Horn, 2005, 2012; Castango \& Brayboy, 2008; Byrnes, 2003; Knowles, 2008). Mathematical inqu[ee]ry requires pedagogical practices that would mobilize students to pose new problems about the world and to problematize the tasks, the mathematical practices and materials, and the very ways of thinking and doing mathematics to interrogate "the 'regimes of the normal' (Warner 1993)" and to push beyond binaries in the elementary mathematics classroom (pp. 186-187; also see Agarwal \& Sengupta-Irving, 2019; Gutstein, 2012).

To more specifically highlight the role of the teacher, consider King's (2018) case study of how a teacher confronted imbalanced gender dynamics in a mixed-sex small-group. When Luci's ideas were systematically rejected by the boys in the group, the teacher stepped in to ask "Luci, how do you feel about the way your group are working together on this problem?" followed by each student reflecting on the issue as follows (see page 460 of the original paper):

\begin{tabular}{|l|l|l|}
\hline 34 & Luci & I feel angry... because I listen to their ideas and they don't do that for me \\
\hline 35 & Teacher & What do you think about that Dev and Jordan? \\
\hline 36 & Jordan & I think it's bad because it's not nice and you should listen \\
\hline
\end{tabular}




\begin{tabular}{|l|l|l|}
\hline 37 & Dev & I think I'm sorry Luci \\
\hline 38 & Lucy & It's okay \\
\hline 39 & Teacher & Is it fair to not listen to other people in your group? \\
\hline 40 & Lucy & No \\
\hline 41 & Dev & It's not fair because we need to share \\
\hline 42 & Jordan & Like share your idea \\
\hline 43 & Teacher & So how can we show respect to each other when we are working together? \\
\hline 44 & Jordan & Be fair to them \\
\hline 45 & Lucy & Listen to their ideas \\
\hline
\end{tabular}

An explicit discussion of sociomathematical skills, fairness, and respect facilitated by the teacher led to more equitable interactions between students right after this episode. Lucy reflected later: "It was more fun because we did it together. We listened to each other" (p. 461).

\section{Summarizing Institutional Responses}

Avoiding sites of gender bias by forming same-sex after-school programs, classrooms, and smallgroups within gender and race heterogeneous classrooms has been one institutional response to managing threats of gender biases while nurturing students' mathematical identities. There are in general at least two problems with this approach. Firstly, there is no escape from patriarchy or heteronormativity, no matter the gender or gender identities of the students in the room. Children, teachers, and curricular materials may still message gender biases and uphold patriarchal norms or norms of dominant masculinity. Biases at the intersection of race, class, and ability as well as issues 
arising out of liberal feminism and meritocratic ideology may also still be present within single-sex spaces. While there are times when single-sex grouping is valuable, especially if the activities engage both boys and girls in challenging patriarchal norms and beliefs, they are currently still positioned as spaces preparing children (to a large extent girls and minoritized boys) to be become ideal neo-liberal subjects (Mendick, 2006; Wilkins, 2012) and gain access to the White western masculinity of mathematics. Secondly, the single-sex response relies on essentialist views of gender: gender as fixed, binary, and uniform. Single-sex education fails to take into consideration the experiences of transgender and gender nonconforming youth or children who may not see their characteristics and traits cleanly fitting into the binaries of femininity or masculinity. As such, there is a danger that single-sex spaces may bolster the epistemic harms of patriarchy and heteronormativity that they were designed to avoid in the first place (Jackson, 2010). Intersectional/fluid identities and discursive performances of gender by children cannot be overlooked when answering questions about redressing epistemic injustice levied by ever-present ideology of patriarchy and ableism in mathematics education (Adhikari, 2019). Deliberately designed learning environments, curriculum, and gender-complex pedagogy that consciously attend to micro-level interactional experiences as well as disrupt macro-level ideologies and beliefs may be needed regardless of the gender compositions of the spaces.

\section{Discussion}

In this review of research, we asked: how do individuals and institutions negotiate, resist, or disrupt epistemic injustice in mathematics education, as established by heteropatriarchy and Whiteness? Firstly, we presented research on ways that gender(race) minoritized students negotiate masculinity in mathematics as individuals. Some of these responses included avoidance of sites of biases, gendered assimilation, resistance, and mitigation. In reviewing this literature, we discussed the nuances of these responses in relation to race, class, dis/ability leading to varying implications for student learning and dignity. In particular, while mechanisms of assimilation and resistance may seem to 
serve White, middle-class students, individual acts do not redress pernicious ideologies of heteropatriarchy and dominant masculinity in mathematics or mathematics education.

Organizing for epistemic justice demands restitution and restoration of the dignity and desires of gender(race) minoritized students. The study of individual acts recognizes that gender(race) minoritized students are unfairly made to defend their rights (to exist, to be engaged, to learn) in day-today experiences of mathematical learning. Whether by assimilation, mitigation, or resistance, these acts move to bracket the harm of heteropatriarchy. Whether resisting through willful non-participation, "loudness", or capitulating to gender binary, gender(race) minoritized students are invoking their "oppositional epistemic agency" (Daukas, 2011) in the face of imminent harm and erasure (epistemic injustice). In that sense, individual acts may contribute to a better understanding of gender(race) minoritized students' "epistemologies of resistance," what Tuck (2009) describes as the first step toward theories of transformation. And yet, relying on students' individual acts - i.e., the acts of those most vulnerable - is largely indefensible. Indeed, the project of gender equity on behalf of gender(race) minoritized students will take far more than individual acts of any kind; it will also require fundamental institutional transformations.

At meso-institutional level, epistemic diversity in mathematics should be messaged to students through math tasks, activities, curricula, detracking policies, and gender-complex pedagogy as well as state and national policies. This includes advancing research on how to transform conceptions of gender for teacher educators, scholars, teachers, and students, especially boys, cisgender, White, middle-class, by more proactively challenging and disrupting gender biases people hold (Rands, 2013). This shifts the gaze from what gender(race) minoritized students do in the face of power, to the structures of power themselves. This also calls for ensuring that the policy-makers are representative of not only gender(race) minoritized people, but specifically include those who deeply understand the harms of heteropatriarchy and are prepared to make amends for the wrongs of the past. As learnt from 
Australian case-studies (Marshall, 2000; Kenway, Willis, Blackmore, \& Rennie, 1993), institutional and national policies play an important role in providing impetus for on-the-ground activism and creating new norms and discourses that are then taken up by educational agents including parents, activists, teachers, teacher-educators, and researchers in confronting the gendered discourses more upfront.

At the macro-level, advancing gender equity as epistemic justice in mathematics education implicates policies and pernicious ideologies of gender that are often ascribed an innocence of "unconscious bias". As Arvin, Tuck, \& Morrill (2013) argue, we must "refuse erasure, but do more than include" because "the project of inclusion can serve to control and absorb dissent rather than allow institutions like feminism and the nation-state to be radically transformed by differing perspectives and goals" (p.17). We take up this challenge to reconsider the notion of gender biases that current literature often deems as unconscious and implicit. We realize that in considering biases to be simply unconscious and implicit, we weaken our responsibilities as scholars who desire epistemic justice for our children. Following Fricker (2007), we argue that much of unconsciousness that exists is a result of lack of "collective interpretive resources" required by those holding the biases to understand the significant experiences and consequences faced by those on the receiving-end of the biases and the deep psychological, emotional, and distributive harms they cause. Dotson (2012) further contends that we do not necessarily lack interpretive resources for recognizing the harmful experiences of biases but often dominant group refuses to acknowledge the interpretive concepts, resources, and epistemologies of resistance (Medina, 2013) that marginalized communities have in fact been building and utilizing all along to make sense of their experiences and persist. Pohlhaus (2012) terms this willful ignorance of dominators that is actively constructed to sustain their dominance and systems of power relations (Sullivan \& Tuana, 2007; Townley, 2011; Tuana \& Sullivan, 2006). This willful ignorance, which serves to uphold White supremacy and heteropatriarchy in mathematics standards, for example, demands a reimagining of what mathematics is, how it is done, and who is recognized as competent, in the absence 
of epistemic harm (see Martin, 2015; Mutegi, 2013). Importantly, ecological and collective actions hold potential to bring together concerned stakeholders to more effectively confront issues of epistemic injustice.

In her "desire-based frameworks" that Tuck (2009) sees as an epistemological shift in research, she forwards the idea of "complex personhood" that "involves making room for the contradictions, for the mis/re/cognitions, usually in an effort to sustain a sense of collective balance" (p. 421). Educational researchers have taken up this call to further develop concepts and resources through microethnographic work and Intersectionality by which to understand student experiences in moment-tomoment interactions in mathematics classrooms and disrupt them. By further continuing to develop these concepts to recognize gender as fluid and non-binary- "complex personhood" - we can better recognize and utilize heterogeneous ways of knowing and being in mathematics. 


\section{References}

Adhikari, K. P. (2019). Identity Construction in Mathematics Learning: A Phenomenological Study of Girl Students. Interdisciplinary Research in Education, 4(1), 1-8.

Agarwal, P., \& Sengupta-Irving, T. (2019). Integrating Power to Advance the Study of Connective and Productive Disciplinary Engagement in Mathematics and Science. Cognition and Instruction, 37(3), 349-366.

Airton, L. (2009). Untangling 'gender diversity': Genderism and its discontents (ie, everyone). Diversity and multiculturalism: A reader, 223-245.

Ansell, E., \& Doerr, H. M. (2000). NAEP findings regarding gender: Achievement, affect, and instructional experiences. Results from the seventh mathematics assessment of the National Assessment of Educational Progress, 73-106.

Archer, L., DeWitt, J., Osborne, J., Dillon, J., Willis, B., \& Wong, B. (2012). "Balancing acts": Elementary school girls' negotiations of femininity, achievement, and science. Science Education, 96(6), 967-989.

Arvin, M., Tuck, E., \& Morrill, A. (2013). Decolonizing feminism: Challenging connections between settler colonialism and heteropatriarchy. Feminist formations, 8-34.

Bailey, B. L., Scantlebury, K. C., \& Johnson, E. M. (1999). Encouraging the beginning of equitable science teaching practice: Collaboration is the key. Journal of Science Teacher Education, 10(3), 159-173.

Baker, D. R. (2002). Good intentions: An experiment in middle school single-sex science and mathematics classrooms with high minority enrollment. Journal of Women and Minorities in Science and Engineering, 8(1).

Barnes, M. (2000). Effects of dominant and subordinate masculinities on interactions in a collaborative learning classroom. In J. Boaler (Ed.), Multiple perspectives on mathematics teaching and learning (pp. 145-169). Westport, CT: Ablex

Bartholomew, H. (2000). Negotiating identity in the community of the mathematics classroom. 
Bartholomew, H. (2005). Top set identities and the marginalisation of girls. In Proceedings of the Fourth Conference on Mathematics, Education and Society.

Bear, J. B., \& Woolley, A. W. (2011). The role of gender in team collaboration and performance. Interdisciplinary science reviews, 36(2), 146-153.

Becker, J. R. (1995). Women's ways of knowing in mathematics. Equity in mathematics education: Influences of feminism and culture, 163-174.

Becker, J. R. \& Jacobs, J. (2001). Introduction. In. Jacobs, J. \& Becker, J. Rossi \& Gilmer, G. (Eds), Changing the Faces of Mathematics (pp. 1-8.). Reston: National Council of Teachers of Mathematics.

Belenky, M. F., Clinchy, B. M., Goldberger, N. R., \& Tarule, J. M. (1986/1997). Women's ways of knowing: The development of self, voice, and mind (2nd ed.). New York: Basic Books.

Birenbaum, M., \& Nasser, F. (2006). Ethnic and gender differences in mathematics achievement and in dispositions towards the study of mathematics. Learning and Instruction, 16(1), 26-40. doi:10.1016/j.learninstruc.2005.12.004

Blaise, M. (2005). A feminist poststructuralist study of children "doing" gender in an urban kindergarten classroom. Early childhood research quarterly, 20(1), 85-108.

Blaise, M. (2012). Playing it straight: Uncovering gender discourse in the early childhood classroom. Routledge.

Blaise, M., \& Taylor, A. (2012). Using Queer Theory to Rethink Gender Equity in Early Childhood Education. Young Children.

Boaler, J. (1997a). Reclaiming school mathematics: The girls fight back. Gender and Education, 9(3), 285305. doi:10.1080/09540259721268

Boaler, J. (1997b). Equity, empowerment and different ways of knowing. Mathematics Education Research Journal, 9(3), 325-342. 
Boaler, J. (2002). Experiencing school mathematics: Traditional and reform approaches to teaching and their impact on student learning (revised \& expanded ed.). Mahwah, NJ: Erlbaum.

Boaler, J., \& Greeno, J. G. (2000). Identity, agency, and knowing in mathematics worlds. Multiple perspectives on mathematics teaching and learning, 1, 171-200.

Boaler, J., \& Staples, M. (2008). Creating mathematical futures through an equitable teaching approach: The case of Railside School. Teachers College Record, 110(3), 608-645.

Bofah, E. A. T., \& Hannula, M. S. (2016). Students' Views on Mathematics in Single-Sex and Coed Classrooms in Ghana. European Journal of Science and Mathematics Education, 4(2), 229-250.

Bowe, A. G., Desjardins, C. D., Covington Clarkson, L. M., \& Lawrenz, F. (2017). Urban elementary singlesex math classrooms: Mitigating stereotype threat for African American girls. Urban Education, 52(3), 370-398.

Brandon, P. R., Newton, B. J., \& Hammond, O. W. (1987). Children's mathematics achievement in Hawaii: Sex differences favoring girls. American Educational Research Journal, 24(3), 437-461.

Brown, R. P., \& Josephs, R. A. (1999). A burden of proof: Stereotype relevance and gender differences in math performance. Journal of personality and social psychology, 76(2), 246.

Brown, S. L., \& Ronau, R. R. (2012). Students' Perceptions of Single-Gender Science and Mathematics Classroom Experiences. School Science and Mathematics, 112(2), 66-87.

BROWN, N., WIGGINS, R., \& SECORD, D. (2008, August). “And God Sits Next to Me": The Role of Religion in Teacher Education Programs. In The Seventh International Conference on Self-Study of Teacher Education Practices.

Buchholz, B., Shively, K., Peppler, K., \& Wohlwend, K. (2014). Hands on, hands off: Gendered access in crafting and electronics practices. Mind, Culture, and Activity, 21(4), 278-297.

Bullock, E. C. (2018). Intersectional analysis in critical mathematics education research: A response to figure hiding. Review of Research in Education, 42(1), 122-145. 
Bunch, A. J. (2015). Epistemic violence in the process of othering: Real-World applications and moving forward. Scholarly Undergraduate Research Journal at Clark, 1(1), 2.

Burton, L. (1995). Moving Towards a Feminist Epistemology of Mathematics. In: Rogers, P. \& Kaiser, G. (Eds.), Equity in Mathematics Education. Influences of Feminism (p. 209-225). London: Falmer Press. Butler, J. (1990) Gender Trouble: Feminism and the Subversion of Identity. New York: Routledge. Butler, J. (1993) `Critically Queer', GLQ: A Journal of Lesbian and Gay Studies 1(1): 17-32.

Butler, J. (2006). Performative acts and gender constitution: An essay in phenomenology and feminist theory. In The RoutledgeFalmer reader in gender \& education (pp. 73-83). Routledge. [originally published in 1988]

Campbell, P. B. 1995. "Redefining the 'Girl Problem in Mathematics.'" In New Directions for Equity in Mathematics Education, ed. W. Secada, E. Fennema, and L. Adajian. Cambridge: Cambridge University Press.

Campbell, P. B., \& Sanders, J. (2002). Challenging the system: Assumptions and data behind the push for single-sex schooling. Gender in policy and practice: Perspectives on single-sex and coeducational schooling, 31-46.

Carpenter, T., Fennema, E., Franke, M., Levi, L., \& Empson, S. (1999). Children's mathematics: Cognitively guided instruction. Portsmouth: Heinemann.

Chen, C. F. J., Jiang, A., Litkowski, E., Elia, A. R., Shuen, J. A., Xu, K., ... \& Schwartz-Bloom, R. D. (2011). Females excelling more in math, engineering, and science (FEMMES): An after-school STEM program for girls that fosters hands-on learning and female-to-female mentorship. Journal of Women and Minorities in Science and Engineering, 17(4).

Cho, S., Crenshaw, K. W., \& McCall, L. (2013). Toward a field of intersectionality studies: Theory, applications, and praxis. Signs: Journal of women in culture and society, 38(4), 785-810. 
Chouinard, R., Vezeau, C., \& Bouffard, T. (2008). Coeducational or single-sex school: does it make a difference on high school girls' academic motivation?. Educational studies, 34(2), 129-144.

Clisby, S., \& Holdsworth, J. (2014). Gendering women: Identity and mental wellbeing through the lifecourse. Policy Press.

Code, L. (1991). What Can She Know?: Feminist Theory and the Construction of Knowledge. Cornell University Press.

Coffey, A., \& James, D. (Eds.). (2016). Masculinity and Education. Routledge.

Cohen, E. G. (1994). Restructuring the classroom: Conditions for productive small groups. Review of educational research, 64(1), 1-35.

Crenshaw, K. (1989). Demarginalizing the intersection of race and sex: A black feminist critique of antidiscrimination doctrine, feminist theory and antiracist politics. u. Chi. Legal f., 139.

Crenshaw, K. (1991). Mapping the margins: Intersectionality, identity politics, and violence against women of color. Stanford Law Review, 43(6), 1241-1299.

Daukas, N. (2011). Altogether now: A virtue-theoretic approach to pluralism in feminist epistemology. In Feminist Epistemology and Philosophy of Science (pp. 45-67). Springer, Dordrecht.

DeBare, I. (2004). Where Girls Come First: The Rise. Fall, and Surprising Revival of Girls.

De Leeuw, S. (2016). Tender grounds: Intimate visceral violence and British Columbia's colonial geographies. Political geography, 52, 14-23.

De Medicci, J. (2006). Rational Goddess/Pagan Witch: History and Hypatia from the Fourth Century AD Through Modernity.

Deutsch, F. M. (2007). Undoing gender. Gender \& society, 21(1), 106-127.

Dossi, G., Figlio, D. N., Giuliano, P., \& Sapienza, P. (2019). Born in the family: preferences for boys and the gender gap in math (No. w25535). National Bureau of Economic Research.

Dotson, K. (2011). Tracking epistemic violence, tracking practices of silencing. Hypatia, 26(2), 236-257. 
Dotson, K. (2012). A cautionary tale: On limiting epistemic oppression. Frontiers: A Journal of Women Studies, 33(1), 24-47.

Else-Quest, N. M., \& Hyde, J. S. (2016). Intersectionality in quantitative psychological research: I. Theoretical and epistemological issues. Psychology of Women Quarterly, 40(2), 155-170.

Esmonde, I. (2009). Mathematics learning in groups: Analyzing equity in two cooperative activity structures. The Journal of the Learning Sciences, 18(2), 247-284.

Esmonde, I. (2011). Snips And Snails And Puppy Dogs'tails: Genderism And Mathematics Education. For the Learning of Mathematics, 31(2), 27-31.

Esmonde, I., Brodie, K., Dookie, L., \& Takeuchi, M. (2009). Social identities and opportunities to learn: Student perspectives on group work in an urban mathematics classroom.

Esmonde, I., \& Langer-Osuna, J. M. (2013). Power in numbers: Student participation in mathematical discussions in heterogeneous spaces. Journal for Research in Mathematics Education, 44(1), 288315.

Fennema, E., \& Sherman, J. (1977). Sex-related differences in mathematics achievement, spatial visualization, and affective factors. American Educational Research Journal, 14(1), 51-71. doi:10.3102/00028312014001051

Fennema, E. H., \& Sherman, J. A. (1978). Sex-related differences in mathematics achievement and related factors: A further study. Journal for Research in Mathematics Education, 9(3), 189-203. doi:10.2307/748997

Fenstermaker, S., \& West, C. (2013). Doing gender, doing difference: Inequality, power, and institutional change. Routledge.

Fluri, J. L., \& Piedalue, A. (2017). Embodying violence: Critical geographies of gender, race, and culture. Fordham, S. (1993). "Those loud Black girls":(Black) women, silence, and gender "passing" in the academy. Anthropology \& Education Quarterly, 24(1), 3-32. 
Forgasz, H. J., Becker, J. R., Lee, K., \& Steinthorsdottir, O., (Eds.). (2010). International perspectives on gender and mathematics education. IAP.

Francis, B. (2000). The gendered subject: students' subject preferences and discussions of gender and subject ability. Oxford Review of Education, 26(1), 35-48.

Francis, B. (2010). Re/theorising gender: Female masculinity and male femininity in the classroom?. Gender and education, 22(5), 477-490.

Franklin, A. J., \& Boyd-Franklin, N. (2000). Invisibility syndrome: A clinical model of the effects of racism on African-American males. American Journal of Orthopsychiatry, 70(1), 33-41.

Fricker, M. (2007). Epistemic injustice: Power and the ethics of knowing. Oxford University Press.

Fulmer, C.L. (2010). Unpacking evidence of gender bias. Journal of Women in Educational Leadership, 8(2), 81-97.

Gholson, M. L. (2016). Clean corners and algebra: A critical examination of the constructed invisibility of black girls and women in mathematics. The Journal of Negro Education, 85(3), 290-301.

Gholson, M. L., \& Martin, D. B. (2019). Blackgirl face: Racialized and gendered performativity in mathematical contexts. ZDM, 51(3), 391-404.

Giuliano, P. (2017). Gender: An historical perspective (No. w23635). National Bureau of Economic Research.

Glazer, A. (2019, March 10). National Mathematics Survey: "You're a girl, you overthink the problem too much.". Retrieved from https://math.mit.edu/wim/2019/03/10/national-mathematics-survev/

Goguen, S. (2016). Stereotype threat, epistemic injustice, and rationality.

Goodell, J. E., \& Parker, L. H. (2001). Creating a connected, equitable mathematics classroom: Facilitating gender equity. Sociocultural research on mathematics education: An international perspective, 411431. 
Gresalfi, M., Martin, T., Hand, V., \& Greeno, J. (2009). Constructing competence: An analysis of student participation in the activity systems of mathematics classrooms. Educational studies in mathematics, 70(1), 49-70.

Gutstein, E. (2012). Reading and writing the world with mathematics: Toward a pedagogy for social justice. Routledge.

Hammrich, P. L. (1997). Confronting the Gender Gap in Science and Mathematics: The Sisters in Science Program.

Hanna, G. (1989). Mathematics achievement of girls and boys in grade eight: Results from twenty countries. Educational Studies in Mathematics, 20(2), 225-232. doi:10.1007/BF00579464

Hanson, S. L., ed. 2009. Swimming against the Tide: African American Girls and Science Education. Philadelphia: Temple University Press.

Harding, S. (2016). Whose science? Whose knowledge?: Thinking from women's lives. Cornell University Press. (Original work published in 1991)

Harris, P. J. (2003). Gatekeeping and remaking: The politics of respectability in African American women's history and Black feminism. Journal of Women's History, 15(1), 212-220.

Hiebert, J., Carpenter, T., Fennema, E., Fuson, K., Human, P., Murray, H., et al. (1997). Making sense: Teaching and learning mathematics with understanding. Portsmouth: Heinemann.

Hottinger, S. N. (2016). Inventing the mathematician: Gender, race, and our cultural understanding of mathematics. SUNY Press.

Hufferd-Ackles, K., Fuson, K. C., \& Sherin, M. G. (2004). Describing levels and components of a math-talk learning community. Journal for research in mathematics education, 81-116.

Hutchison, J. E., Lyons, I. M., \& Ansari, D. (2019). More similar than different: Gender differences in children's basic numerical skills are the exception not the rule. Child development, 90(1), e66-e79. 
Hyde, J. S., Fennema, E., Ryan, M., Frost, L. A., \& Hopp, C. (1990). Gender comparisons of mathematics attitudes and affect: A meta-analysis. Psychology of women quarterly, 14(3), 299-324.

Hyde, J. S., \& Jaffee, S. (1998). Perspectives from social and feminist psychology. Educational Researcher, 27(5), 14-16. doi:10.3102/0013189X027005014

Inzlicht, M., \& Ben-Zeev, T. (2000). A threatening intellectual environment: Why females are susceptible to experiencing problem-solving deficits in the presence of males. Psychological Science, 11(5), 365371.

Jackson, J. (2010). 'Dangerous presumptions': how single-sex schooling reifies false notions of sex, gender, and sexuality. Gender and Education, 22(2), 227-238.

Jacobs, J. E., \& Becker, J. R. (1997). Creating a gender-equitable multicultural classroom using feminist pedagogy. Multicultural and gender equity in the mathematics classroom: The gift of diversity, 107114.

JACKSON, M. (1987) Making sense of school, in: A. POLLARD (Ed.) Children and their Primary Schools: a new perspective (Lewes, Falmer Press).

Jackson, C., \& Warin, J. (2000). The importance of gender as an aspect of identity at key transition points in compulsory education. British educational research journal, 26(3), 375-391.

Jorgenson, J. (2002). Engineering selves: Negotiating gender and identity in technical work. Management Communication Quarterly, 15(3), 350-380.

Joseph, N. M., Hailu, M., \& Boston, D. (2017). Black women's and girls' persistence in the P-20 mathematics pipeline: Two decades of children, youth, and adult education research. Review of Research in Education, 41(1), 203-227.

Kaplan, S. E. (2013). Exploring the Narratively-Constructed Mathematical Identities of Latina Bilingual Middle School Students. 
Kenway, J., Willis, S., Blackmore, J., \& Rennie, L. (1993). Learning from girls: What can girls teach feminist teachers?. Critical Studies in Education, 34(1), 63-77.

Kersey, A. J., Braham, E. J., Csumitta, K. D., Libertus, M. E., \& Cantlon, J. F. (2018). No intrinsic gender differences in children's earliest numerical abilities. npj Science of Learning, 3(1), 1-10.

Kersey, A. J., Csumitta, K. D., \& Cantlon, J. F. (2019). Gender similarities in the brain during mathematics development. npj Science of Learning, 4(1), 1-7.

King, C. (2018). Issues of Equity in a Mathematical Inquiry Classroom. Mathematics Education Research Group of Australasia.

Klopfenstein, K. (2005). Beyond test scores: The impact of Black teacher role models on rigorous math taking. Contemporary Economic Policy, 23(3), 416-428.

Kombe, D., Che, S. M., Carter, T. L., \& Bridges, W. (2016). Student Academic Self-Concept and Perception of Classroom Environment in Single-Sex and Coeducational Middle Grades Mathematics Classes. School Science and Mathematics, 116(5), 265-275.

Kumashiro, K. (2002). Troubling education:" Queer" activism and anti-Oppressive pedagogy. Routledge.

Kusimo, P. S., Carter, C. S., \& Keyes, M. C. (1990, April). I'd Like To Go to Harvard but I Don't Know Where It Is". In Paper presented at the American Educational Research Association. Appalachia Educational Lab., Charleston, WV.

Langer-Osuna, J. M. (2016). The social construction of authority among peers and its implications for collaborative mathematics problem solving. Mathematical Thinking and Learning, 18(2), 107-124. Langer-Osuna, J. M. (2017). Authority, identity, and collaborative mathematics. Journal for Research in Mathematics Education, 48(3), 237-247.

Lave, J. (1988). Cognition in practice: Mind, mathematics and culture in everyday life. Cambridge University Press. 
Leder*, G. (2004). Gender differences among gifted students: Contemporary views. High ability studies, 15(1), 103-108.

Lei, J. L. (2003). (Un) Necessary toughness?: Those" loud Black girls" and those" quiet Asian boys". Anthropology \& Education Quarterly, 34(2), 158-181.

Lester, J., Yamanaka, A., \& Struthers, B. (2016). Gender microaggressions and learning environments: The role of physical space in teaching pedagogy and communication. Community College Journal of Research and Practice, 40(11), 909-926.

Leyva, L. A. (2016). An Intersectional Analysis of Latin@ College Women's Counter-Stories in Mathematics. Journal of Urban Mathematics Education, 9(2), 81-121.

Leyva, L. A. (2017). Unpacking the male superiority myth and masculinization of mathematics at the intersections: A review of research on gender in mathematics education. Journal for Research in Mathematics Education, 48(4), 397-433.

Lim, J. H. (2008). Adolescent girls' construction of moral discourses and appropriation of primary identity in a mathematics classroom. ZDM, 40(4), 617-631.

Lindberg, S. M., Hyde, J. S., Petersen, J. L., \& Linn, M. C. (2010). New trends in gender and mathematics performance: A meta-analysis. Psychological Bulletin, 136(6), 1123-1135. doi:10.1037/a0021276

Lu, F., \& Anderson, M. L. (2015). Peer effects in microenvironments: The benefits of homogeneous classroom groups. Journal of Labor Economics, 33(1), 91-122.

Machi, L. A., \& McEvoy, B. T. (2016). The literature review: Six steps to success. Corwin Press.

Marcus, J. (1988). Invincible mediocrity: The private selves of public women. The Private Self: Theory and Practice of Women's Autobiographical Writings, 114-46.

Marshall, C. (2000). Policy mechanisms for gender equity in Australia. Educational Policy, 14(3), 357-384.

Martin, D. B. (2015). The Collective Black and" Principles to Actions". Journal of Urban Mathematics Education, 8(1), 17-23. 
McCullough, S. (2015). Middle School Girls in Postfeminist Times.

McNamee, S. J., \& Miller, R. K. (2009). The meritocracy myth. Rowman \& Littlefield.

Medina, J. (2013). The epistemology of resistance: Gender and racial oppression, epistemic injustice, and the social imagination. Oxford University Press.

Mendick, H. (2005). A beautiful myth? The gendering of being/doing 'good at maths'. Gender and education, 17(2), 203-219.

Mendick, H. (2006). Masculinities in mathematics. McGraw-Hill Education (UK).

Mendick, H., Allen, K., \& Harvey, L. (2015). 'We can get everything we want if we try hard': Young people, celebrity, hard work. British Journal of Educational Studies, 63(2), 161-178.

Meyer, P. (2008). Learning separately: The case for single-sex schools. Education Next, 8(1), 1022. Meyer, 2008

Meyer, E. J., \& Leonardi, B. (2018). Teachers' professional learning to affirm transgender, non-binary, and gender-creative youth: Experiences and recommendations from the field. Sex Education, 18(4), 449-463.

Miller, E., Manz, E., Russ, R., Stroupe, D., \& Berland, L. (2018). Addressing the epistemic elephant in the room: Epistemic agency and the next generation science standards. Journal of Research in Science Teaching, 55(7), 1053-1075.

Mogari, D. (2017). Using culturally relevant teaching in a co-educational mathematics class of a patriarchal community. Educational Studies in Mathematics, 94(3), 293-307.

Morris, E. W. (2007). "Ladies" or "loudies"? Perceptions and experiences of Black girls in classrooms. Youth \& Society, 38(4), 490-515.

Morrow, C., \& Schowengerdt, I. (2008). Stepping beyond high school mathematics: A case study of high school women. ZDM, 40(4), 693-708. 
Moss-Racusin, C. A., Pietri, E. S., Hennes, E. P., Dovidio, J. F., Brescoll, V. L., Roussos, G., \& Handelsman, J. (2018). Reducing STEM gender bias with VIDS (video interventions for diversity in STEM). Journal of Experimental Psychology: Applied, 24(2), 236.

Mutegi, J. W. (2011). The inadequacies of "Science for All" and the necessity and nature of a socially transformative curriculum approach for African American science education. Journal of Research in Science Teaching, 48(3), 301-316.

Neblett Jr, E. W., Philip, C. L., Cogburn, C. D., \& Sellers, R. M. (2006). African American adolescents' discrimination experiences and academic achievement: Racial socialization as a cultural compensatory and protective factor. Journal of Black psychology, 32(2), 199-218.

Nelson, L. (2010). Who knows: From Quine to a feminist empiricism. Temple University Press. (Original work published in 1990)

Niederle, M., \& Vesterlund, L. (2010). Explaining the gender gap in math test scores: The role of competition. Journal of Economic Perspectives, 24(2), 129-44.

Pahlke, E., Hyde, J. S., \& Allison, C. M. (2014). The effects of single-sex compared with coeducational schooling on students' performance and attitudes: A meta-analysis. Psychological bulletin, 140(4), 1042.

Park, H., Behrman, J. R., \& Choi, J. (2018). Do single-sex schools enhance students' STEM (science, technology, engineering, and mathematics) outcomes?. Economics of Education Review, 62, 35-47.

Parker, L. R., Monteith, M. J., Moss-Racusin, C. A., \& Van Camp, A. R. (2018). Promoting concern about gender bias with evidence-based confrontation. Journal of Experimental Social Psychology, 74, 8-23.

Pennington, J. L., Brock, C. H., Abernathy, T. V., Bingham, A., Major, E. M., Wiest, L. R., \& Ndura, E. (2012). Teacher Educators' Dispositions: Footnoting the present with stories from our pasts. Studying Teacher Education, 8(1), 69-85. 
Pohlhaus Jr, G. (2012). Relational knowing and epistemic injustice: Toward a theory of willful hermeneutical ignorance. Hypatia, 27(4), 715-735.

Rands, K. E. (2009a). Considering transgender people in education: A gender-complex approach. Journal of Teacher Education, 60(4), 419-431.

Rands, K. (2009b). Mathematical Inqu[ee]ry: beyond 'Add-Queers-and-Stir'elementary mathematics education. Sex Education, 9(2), 181-191.

Rands, K. E. (2011). Affirming difference, generating problems, and becoming-democratic in mathematics education.

Rands, K. (2013). Supporting transgender and gender-nonconforming youth through teaching mathematics for social justice. Journal of LGBT Youth, 10(1-2), 106-126.

Rands, K. (2016). Mathematical inqueery. In Critical Concepts in Queer Studies and Education (pp. 183192). Palgrave Macmillan, New York.

Rands, K., McDonald, J., \& Clapp, L. (2013). Landscaping classrooms toward queer utopias. In A critical inquiry into queer utopias (pp. 149-172). Palgrave Macmillan, New York.

Rawls, A. W., \& David, G. (2005). Accountably other: Trust, reciprocity and exclusion in a context of situated practice. Human Studies, 28(4), 469-497.

Reid, P. T., \& Roberts, S. K. (2006). Gaining options: A mathematics program for potentially talented atrisk adolescent girls. Merrill-Palmer Quarterly (1982-), 288-304.

Riegle-Crumb, C. (2006). The path through math: Course sequences and academic performance at the intersection of race-ethnicity and gender. American Journal of Education, 113(1), 101-122. doi:10.1086/506495

Riegle-Crumb, C., \& Humphries, M. (2012). Exploring bias in math teachers' perceptions of students' ability by gender and race/ethnicity. Gender \& Society, 26(2), 290-322. 
Rodd, M., \& Bartholomew, H. (2006). Invisible and special: Young women's experiences as undergraduate mathematics students. Gender and Education, 18(1), 35-50.

Scantlebury, K., Johnson, E., Lykens, S., Clements, R., Gleason, S., \& Lewis, R. (1996). Beginning the cycle of equitable teaching: The pivotal role of cooperating teachers. Research in Science Education, 26(3), 271-281.

Sengupta-Irving, T. (2009). Partnerships as mathematical practice: How managing the dual dimensions of collaboration organize community in a low-track algebra class. Stanford University.

Sengupta-Irving, T. (2014). Affinity through Mathematical Activity: Cultivating Democratic Learning Communities. Journal of Urban Mathematics Education, 7(2), 31-54.

Sengupta-Irving, T., \& Vossoughi, S. (2019). Not in their name: re-interpreting discourses of STEM learning through the subjective experiences of minoritized girls. Race Ethnicity and Education, 22(4), 479-501.

Seron, C., Silbey, S., Cech, E., \& Rubineau, B. (2018). "I am Not a Feminist, but...": Hegemony of a Meritocratic Ideology and the Limits of Critique Among Women in Engineering. Work and Occupations, 45(2), 131-167.

Shaw, S. M. (2001). The family leisure dilemma: Insights from research with Canadian families. World Leisure Journal, 43(4), 53-62.

Sheldon, J. (2019). Towards a Queer Curriculum of Infinity. In STEM of Desire (pp. 307-318). Brill Sense. Singleton, G. E. (2005). Courageous Conversations About Race: A Guide for Achieving Equity in Schools. Slavin, R. E. (1996). Research on cooperative learning and achievement: What we know, what we need to know. Contemporary educational psychology, 21(1), 43-69.

Solomon, Y., Lawson, D., \& Croft, T. (2011). Dealing with 'fragile identities': resistance and refiguring in women mathematics students. Gender and Education, 23(5), 565-583. 
Solomon, Y., Radovic, D., \& Black, L. (2016). “I can actually be very feminine here": contradiction and hybridity in becoming a female mathematician. Educational Studies in Mathematics, 91(1), 55-71.

Spencer, M. B., Fegley, S. G., \& Harpalani, V. (2003). A theoretical and empirical examination of identity as coping: Linking coping resources to the self processes of African American youth. Applied Developmental Science, 7(3), 181-188.

Steffens, M. C., Jelenec, P., \& Noack, P. (2010). On the leaky math pipeline: Comparing implicit mathgender stereotypes and math withdrawal in female and male children and adolescents. Journal of Educational Psychology, 102(4), 947.

Steward, R. J., Jo, H. I., Murray, D., Fitzgerald, W., Neil, D., Fear, F., et al. (1998). Psychological adjustment and coping styles of urban African American high school students. Journal of Multicultural Counseling and Development, 26, 70-82.

Stinson, David. (2004). Mathematics as "gateKeeper" (?): Three theoretical perspectives that aim toward empowering all children with a key to the gate. The Mathematics Educator. 14. 8-18.

Strom, K., Abi-Hanna, R., Abrams, L., Dacey, C., \& Dauplaise, J. (2014). Exploring and connecting lines of flight in a self-study community. In Gender, feminism, and queer theory in the self-study of teacher education practices (pp. 31-43). Brill Sense.

Sullivan, S., \& Tuana, N. (Eds.). (2007). Race and epistemologies of ignorance. Suny Press.

Taylor, M., Ayari, C., Kintish, R., Jedick, N., Lemley, J., Lormand, K., \& Weinstein, L. (2018). Using selfstudy to push binary boundaries and borders: Exploring gender and sexuality in teacher education. Pushing boundaries and crossing borders: Self-study as a means for knowing pedagogy, 229-236.

Townley, C. (2011). A defense of ignorance: Its value for knowers and roles in feminist and social epistemologies. Lexington books.

Tuana, N., \& Sullivan, S. (2006). Introduction: Feminist epistemologies of ignorance. Hypatia, 21(3), vii-ix. 
Tuck, E. (2009). Suspending damage: A letter to communities. Harvard Educational Review, 79(3), 409428.

Tyack, D. B. (1993). Constructing Difference: Historical Reflections on Schooling and Social Diversity. Teachers College Record, 95(1), 8-34.

Vale, C., \& Bartholomew, H. (2008). Gender and mathematics: Theoretical frameworks and findings. Research in Mathematics Education in Australasia, 2004-2007, 271-290.

Vale, C. M., \& Leder, G. C. (2004). Student views of computer-based mathematics in the middle years: does gender make a difference?. Educational studies in mathematics, 56(2-3), 287-312.

Valera, S., \& Takeuchi, M. (2018). Students' Identities and Collaboration in Mathematics Group Work. Vrooman, M. K. (2009). An examination of the effects of single-gender classes on reading and mathematics achievement test scores of middle school students.

Walls, F. (2010). Freedom to choose? Girls, mathematics and the gendered construction of mathematical identity. International perspectives on gender and mathematics education, 87-110.

Warin, J. (1998) The role of gender in the development of the young child's sense of self within the social context of early school experiences, unpublished PhD thesis, Lancaster University.

Webb, N. M., \& Palincsar, A. S. (1996). Group processes in the classroom. Prentice Hall International.

Weber, S. J., \& Mitchell, C. A. (2000, July). Prom dresses are us? Excerpts from collective memory work. In Exploring Myths and L egends of T eacher Education. Proceedings of the Third International Conference of the Self-Study of Teacher Education Practices (Vol. 2, pp. 248-251).

West, C., \& Zimmerman, D. H. (2009). Accounting for doing gender. Gender \& society, 23(1), 112-122.

White, E. F. (2010). Dark continent of our bodies: Black feminism \& politics of respectability. Temple University Press.

Whitfield, B. J. (1995). The Beauty of Reasoning: A Reexamination of Hypatia of Alexandra. The Mathematics Educator, 6(1). 
Wilcox, S., Watson, J., \& Paterson, M. (2004). Self-study in professional practice. In International handbook of self-study of teaching and teacher education practices (pp. 273-312). Springer, Dordrecht.

Wilkins, A. (2012). Push and pull in the classroom: competition, gender and the neoliberal subject. Gender and Education, 24(7), 765-781.

Wolfe, M. J. (2019). Smart girls traversing assemblages of gender and class in Australian secondary mathematics classrooms. Gender and Education, 31(2), 205-221.

Wun, C. (2016). Unaccounted foundations: Black girls, anti-Black racism, and punishment in schools. Critical Sociology, 42(4-5), 737-750. 